\title{
LA LITERATURA DE LOS JESUITAS EXPULSOS DE LA PROVINCIA DEL PARAGUAY. MEMORIAS DE UNA INTENSA LABOR
}

\section{Literature of the Jesuits expelled from the provincial of Paraguay. Memories of intense work}

\author{
Carlos A. PAGE \\ CONICET. Consejo Nacional de Investigaciones Científicas y Técnicas (Argentina) \\ capage1@hotmail.com
}

Fecha de recepción: 12/01/2017

Fecha de aceptación definitiva: 14/03/2018

RESUMEN: El exilio de los jesuitas en Italia, a pesar de la tribulación que implica, fue sumamente fructífero en la labor literaria de quienes pretendían sobrellevar esa carga. Compendiamos en este artículo, a los fines de divulgación y descripción general de una amplia variedad temática, el trabajo de los jesuitas de la provincia del Paraguay; escritores de distintos orígenes que se expresaron en obras abocadas no solo a la filosofía y la teología, sino también a la ciencia y a las culturas originarias. Algunas alcanzaron las prensas, otras quedaron inéditas y no pocas se perdieron. Aunque siempre estarán presentes las memorias y recuerdos de una vida feliz trocada en desdicha. Un quehacer que buscaba afirmar su propia identidad para encontrar la verdadera libertad.

Palabras clave: Compañía de Jesús; Provincia Jesuítica del Paraguay; exilio; literatura de los expulsos.

ABSTRACT: The exile of the Jesuits in Italy, in spite of the tribulation it implied, was extremely fruitful in the literary work of those who tried to bear that burden. In this article, for the purposes of dissemination and general description of a wide variety of themes, we have included in this article the work of the Jesuits of the 
province of Paraguay; writers of different origins who expressed themselves in works devoted not only to philosophy and theology, but also to science and to native cultures. Some reached the presses, others were unpublished and a few were lost. Although the memories and memories of a happy life exchanged in misery will always be present. A task that sought to assert its own identity to find true freedom.

Key words: Company of Jesus; Jesuit Province of Paraguay; exile; literature of the expelled.

\section{LOS LARGOS AÑOS EN EL DESTIERRO}

Nada fácil les resultó la vida en el exilio a esa gran masa de "gente ociosa», como despectivamente calificó a los expulsos el secretario de Estado de Clemente XIII, cardenal Luis Torrigiani. Los más de 5.000 individuos de las once provincias españolas debían residir en los tres Estados Pontificios septentrionales: Bolonia, Ferrara y Rávena, es decir, en la región de Emilia-Romagna. Pero no fueron a los colegios jesuíticos, pues el general Lorenzo Ricci temía que colapsara la estructura económica de la Asistencia de Italia que en su momento debió soportar la subsistencia de los expulsos de Portugal y luego Francia, y por ese tiempo la inminente llegada de los jesuitas napolitanos, sicilianos y parmesanos ${ }^{1}$. Aunque a diferencia de aquellos, Carlos III ordenó una pensión vitalicia proveniente de la administración de las Temporalidades, que quedaría sin efecto si abandonaban las ciudades asignadas. Mísera manutención fija que fue perdiendo valor a medida que la inflación generada en aquellos tiempos recrudecía el poder adquisitivo. Pero los familiares y sobre todo los amigos americanos no dejaron de ayudar a los jesuitas enviándoles dinero, como lo hicieron los hermanos Funes desde Córdoba, o el doctor Félix Zuloaga desde Buenos Aires, o el doctor Maciel desde Santa Fe. Incluso algunos pocos jesuitas del Paraguay, por el reconocimiento a sus escritos, fueron beneficiados por la Corona con una doble pensión, tal el caso de los PP. Gaspar Juárez, Joaquín Millás, Juan Francisco Aznar y Francisco Javier Iturri. Otros en cambio sufrieron arbitrariedades que alcanzaron a la confiscación de sus textos como el por entonces polémico P. Pedro Campos².

Los jesuitas del Paraguay después de un largo y cansador viaje de 14 meses, donde murieron varios ancianos, arribaron a su destino en la ciudad de Faenza, excepto los extranjeros que volvieron a sus países. Unos pocos se distribuyeron en Rávena, Brisighella y los menos en Imola. En Faenza se repartieron en el seminario, cuyos alumnos se encontraban de vacaciones, y en el monasterio de los

1. GuAsti, Niccoló. "Rasgos del exilio italiano de los jesuitas españoles». Hispania Sacra. Madrid, 2009, LXI, 123, p. 259.

2. Hervás y PANDURo, Lorenzo. Biblioteca Jesuítico-Española (1759-1799). Estudio introductorio, edición crítica y notas Antonio Astorgano Abajo. Madrid: Libris, 2007, p. 80. 
Siervos de María o Servitas. Obtuvieron ayuda de los jesuitas de Faenza en los PP. Pedro Pablo Canestri, Luis Correa y del propio rector del colegio que les permitió tomar de la biblioteca todos los libros que quisieran ${ }^{3}$. También recibieron atenciones del conde Francisco Cantoni, hermano del obispo Antonio, fallecido el año anterior, quien luego de ver a los expulsos deambulando de casa en casa, llevó a su residencia a los ubicados en el seminarió. El palacio que acogió a unos ochenta jesuitas lo llamaban L'Isola, porque se encontraba en una isla, circundada por el río Lamone, bombardeado y destruido en la Segunda Guerra Mundial.

A pesar de todas las dificultades que surgieron, los jesuitas pudieron reconstruir su estructura funcional y jerárquica. El 17 de octubre de 1768 fue designado provincial en el exilio el P. José de Robles ${ }^{5}$ y rector del Colegio Máximo, el P. Domingo Muriel. Ambos habían sido los últimos procuradores en Europa de la provincia y habían llegado a Faenza en aquella fecha. El P. Robles transfirió a algunos jesuitas a Ferrara e Imola, quedándose en Faenza donde, además de conseguir sede, determinó hacer un fondo común con las pensiones, pero sobre todo fortalecer los lazos de lealtad y obediencia. Por su parte, el P. Muriel organizó el Colegio Máximo con siete profesores ${ }^{6}$, pero, cuando Carlos III advirtió que el general había designado nuevos provinciales, tomó el hecho como una ofensa y lo obligó, a mediados de 1769 , a que revocara la orden de dar nombramientos a provincias con designaciones españolas. De tal forma y para sortear este mandato, el P. Lorenzo Ricci decidió cambiar esos nombres por el de santos protectores. Fue

3. Hernández SJ, Pablo. Colección de libros y documentos referentes á la historia de América. Tomo VII. El extrañamiento de los jesuitas del Río de la Plata y de las misiones del Paraguay. Madrid: Librería General de Victoriano Suárez, 1908, p. 245.

4. El P. Miranda al escribir la biografía del P. Muriel recuerda con sobrada gratitud la figura de Cantoni, quien los ayudó en todo cuanto podía. Incluso también a los jesuitas de Quito les ofreció el palacio llamado San Nebulón que había sido el hospital de la ciudad. El P. Ricci ante tanta generosidad le envió carta de hermandad con la que lo hacía partícipe de todos los bienes espirituales de la religión (Miranda SJ, Francisco Javier. Vida del Venerable sacerdote Don Domingo Muriel, religioso un tiempo de la abolida Compañia de Jesús y último provincial de su Provincia del Paraguay, escrita por un discípulo suyo sacerdote de la misma Compañía. Córdoba: Universidad Nacional de Córdoba, 1916, p. 318).

5. Sucedió al P. Manuel Vergara (1711-1770), quien había sido designado provincial en setiembre de 1766 y se encontraba en la reducción de Yapeyú cuando llegaron las tropas que lo arrestaron y luego trasladaron a España. Pero el sacerdote se hallaba gravemente enfermo y permaneció en el Puerto de Santa María donde murió el 15 de mayo de 1770 [STORni SJ, Hugo. Catálogo de los jesuitas de la Provincia del Paraguay (Cuenca del Plata) (1585-1768). Roma: Institutum Historicum S.I., 1980, p. 302]. Una biografía suya en PERAMÁs SI, José Manuel. Vida y obra de seis humanistas. Buenos Aires: Ed. Huarpes, 1946 [1791], pp. 37-91. Según el P. Furlong para la expulsión se inventariaron diez manuscritos de su autoría (Furlong SJ, Guillermo. Nacimiento y desarrollo de la filosofía en el Río de la Plata. 1536-1810. Buenos Aires: Ed. Guillermo Kraft Limitada, 1952, p. 156).

6. Dos de Teología Dogmática, uno de Moral, otro de Derecho Canónico, otro de Sagrada Escritura, uno de Filosofía y uno de Retórica, para unos 60 estudiantes. Tal cual funcionaba en Córdoba (Hernández SJ, Pablo. Colección de libros y documentos, op. cit., p. 246). 
en ese momento que la provincia del Paraguay comenzó a llamarse en el exilio provincia de San José.

El P. Robles decidió trasladar el colegio a otra residencia propiedad del canónigo penitenciario don Domingo María Fanelli. Los motivos fueron diversos, en primer lugar la estrechez de la casa, pero hay que señalar el temblor del primer día de 1769 que por una cuestión supersticiosa, parte de la población culpó del siniestro a la presencia de los jesuitas y unas mujeres hasta intentaron incendiar la casa del conde. Para la mudanza debieron convencer al propietario el obispo y el propio Cantoni para que les alquilara la residencia donde él mismo habitaba una pequeña parte. Ángeles en vez de hombres le comentaba que tenía en su casa al P. Ricci. De allí que por muchos años se denominaba la «calle de los ángeles» a la que pasaba por aquella residencia ${ }^{7}$.

En 1771 el general Ricci designó provincial al P. Muriel, cargo que mantuvo hasta la extinción. Al igual que el P. Robles, que pasó a ser rector del colegio. El flamante y carismático provincial recorrió las casas de Faenza, Rávena y Brisighella, a sabiendas de que la supresión era inminente. Fue por entonces que tradujo los Ejercicios de Diertins a los fines de elevar la alicaída moral del dramático exilio y redactó su carta sobre el modo de conservar el espíritu ignaciano.

Con el breve Dominus ac Redemptor del 21 de junio de 1773 se interrumpió el proceso organizativo del exilio y las comunidades debieron disolverse para dispersarse por el centro y norte de Italia, aunque la mayoría permaneció en las ciudades asignadas hasta la llegada de los franceses en 1796, pues no solo habían estrechado lazos de amistad con la nobleza, que les permitía tener trabajo en la educación de sus hijos, sino que muchos ya eran personas mayores que les costaba trasladarse.

Encargado de notificar el breve a los jesuitas del Paraguay fue el obispo de Faenza Vitale Giuseppe de' Buoi, quien convocó a los jesuitas a su palacio para leerles el documento que ponía fin a la Compañía de Jesús ${ }^{8}$. Siguieron años de zozobra donde aparecían vagos destellos de esperanza en el regreso, como los decretos reales de 1797 y 1798 que les permitían volver a conventos o a las casas de sus parientes en España. Solo cinco jesuitas consiguieron pasaporte para América. A Buenos Aires llegó el P. Diego León de Villafañe, aunque por ese tiempo también alcanzaron el Río de la Plata los secularizados Pedro Arduz de Jujuy, que lo hizo junto a su pequeño hijo, y José Rivadavia de Buenos Aires, que fue deportado en 1803, aunque regresó y murió en su tierra natal una década después.

Los que se quedaron en España fueron expulsados nuevamente de la península, regresando a Italia hasta la toma de Roma por parte de los franceses en 1808 donde fueron obligados a jurar fidelidad al nuevo rey de España, José Bonaparte.

7. Miranda SJ, Francisco Javier. Vida del Venerable... Op. cit., p. 333.

8. MiRAnda SJ, Francisco Javier. Vida del Venerable... Op. cit., p. 369. 
Obviamente, se negaron y fueron perseguidos y encarcelados como lo fue el santafecino Francisco Javier Iturri.

Para la Restauración, primero en Nápoles y Sicilia en 1804 y una década después en el resto del mundo, quedaban vivos pocos jesuitas, de los que solo uno había regresado conservando la investidura jesuita: el mencionado P. Villafañe. Otros pocos quedaron en Europa y fueron parte de la nueva Compañía de Jesús, entre ellos los PP. Pedro Ramón Ganuza (1744-1829), Joaquín Lucas Usón (17431816) y los criollos Juan Francisco Ortiz de Ocampo (1729-1816), Francisco Iturri (1738-1822) y Joaquín Camaño (1737-1820).

\subsection{La producción literaria del exilio}

La literatura escrita por los jesuitas en su estadía en Italia se destacó notablemente. Ello se debe -como escribe Batllori- al estado cultural de las diversas provincias españolas ante la expulsión? ${ }^{9}$. De tal manera que surgieron escritores de suma significación que han conformado una suerte de literatura hispano-italiana. Ya había literatos célebres dentro de los religiosos expulsos de la Compañía de Jesús como Juan Andrés, Esteban Terreros y Francisco José de Isla, entre otros. Pero la gran producción estaba reservada en gran medida para una estirpe de hombres que, sobre todo, deseaban hacer conocer al mundo su vida cotidiana misional en países lejanos y llenos de peligros. Sobresalen en este sentido los llegados de América, nutridos de una experiencia educacional y misional que los distinguía. Los educadores derivaron en publicistas y los misioneros en la producción fundamentalmente de obras de carácter etnográfico, lingüístico, teológico y geográfico, convirtiéndose en fuentes primordiales del, por ejemplo, enciclopedismo de Hervás, el padre de la filología moderna, que recibió notable ayuda de jesuitas del Paraguay como José Guevara, José Pellejá, Ramón María de Termeyer, José Cardiel, José Manuel Peramás y José Sánchez Labrador ${ }^{10}$, pero sobre todo de Joaquín Camaño, quien proporcionó sus conocimientos sobre las lenguas chiriguana y las del Brasil; rectificó las noticias de Machoni sobre la lengua lule; escribió sobre la afinidad entre las lenguas maya, yapitalagia, mocobí y abipona, además de las lenguas de los payaguas, guanes, porrudos, guayakés y omaguacas.

Una primera etapa literaria en Italia va a estar signada por los relatos conmovedores del exilio, donde los jesuitas dejaron escritos testimoniales de aquel hecho. Obviamente, todos fueron textos prohibidos e inéditos que se publicaron

9. BATLlori SI, Miguel. La cultura hispano-italiana de los jesuitas expulsos, españoles, hispanoamericanos, filipinos, 1767-1814. Madrid: Ed. Gredos, 1966, p. 23.

10. El P. Furlong señala además a los PP. Juan Molina (Catamarca, 1734-Rávena, 1778), Manuel Durán (Monterde, 1729-Verona, 1797), Francisco Burgés (Pamplona, 1709-Faenza, 1777), Tomás Borrego (Écija, 1728-Faenza, 1790) y José Ferragut (Palma de Mallorca, 1748-Rávena, 1787) (FurLong SJ, Guillermo. "Lorenzo Hervás y las lenguas indígenas americanas». Estudios, Buenos Aires, 1927, 32, p. 294). 
mucho tiempo después ${ }^{11}$. Mientras que, ya establecidos, se abocaron a escribir en forma sistemática, lo que algunos habían comenzado a concebir en América y continuaban con sus memorias que se afirmaban con el paso del tiempo y en el recuerdo imborrable de los buenos tiempos del pasado.

Esta situación se relacionó con los escritos del contexto europeo que desvalorizaba no solo la empresa colonizadora española, sino también las culturas originarias y la naturaleza del nuevo continente, y, por cierto, la labor evangelizadora de los jesuitas. Nos referimos principalmente a las obras del holandés Cornelio de Pauw (1768-1769), del abate francés Guillaume Raynal (1770) y el escocés William Robertson (1777). Los jesuitas, como intérpretes principales de los sentimientos regionalistas, fueron los primeros detractores de esas posturas como el chileno Manuel de Salas, el mexicano Francisco Javier Clavijero o el peruano Juan Pablo Viscardo Guzmán, entre muchos otros. Y hasta resultaron estimulados para responder, y no solo por convicción, sino también porque el conde de Floridablanca comenzó a ofrecer premios de pensiones dobles a los expulsos para que escribieran en contra de aquellos ${ }^{12}$. Era una clara necesidad de la monarquía borbónica controlar la historiografía americanista y para ello disponían del intelecto jesuita, aunque presionado como una posibilidad y esperanza de regreso. Pero esa defensa no fue ejercida por los jesuitas con un criterio único, pues así como unos reivindicaban la intervención de España al grado de convertirse en apologetas, otros preferían enaltecer sus vivencias con las culturas originarias, resaltando la tierra y los hombres americanos. Nos referimos a los jesuitas del norte de Europa y fundamentalmente a los propios criollos.

Un ejemplo dentro de los jesuitas del Paraguay fue el mencionado P. Iturri, de quien nos ocuparemos en particular. Pero en toda América se produjeron obras exaltando el continente como los trabajos de los PP. Francisco Javier Clavijero de México, Juan Ignacio Molina de Chile, Juan de Velasco de Quito, Antonio Julián y Filippo Antonio Gilij de Venezuela.

Efectivamente los jesuitas se dividieron en sus apreciaciones, entre hispanos europeos y criollos, aunque juntos cultivaban una ideología regionalista prenacional que aumentó con la melancolía de la distancia y los sufrimientos que les ocasionó el exilio. De estas tendencias, la obra de José Manuel Peramás comparando la República de Platón con las reducciones guaraníticas (1793) ya no tiene solo carácter religioso, sino que evidencia sus europeizadas ideas.

En la antigua provincia del Paraguay se destacaron varios profesores escritores que trabajaron diversas temáticas, resaltando el valor de las letras clásicas, la filosofía y también la historia natural, pues la ciencia ocupó un lugar preponderante.

11. Una compilación completa de todos ellos en PAGE, Carlos A. Relatos desde el exilio. Memorias de los jesuitas expulsos de la antigua Provincia del Paraguay. Asunción del Paraguay: Servilibro, 2011.

12. Fernández Arrillaga, Inmaculada. El destierro de los jesuitas castellanos (1767-1815). Salamanca: Junta de Castilla y León, pp. 100-110. 
Pero muchas de estas obras fueron publicaciones póstumas que penetraron el siglo XIX y profundamente aún en nuestros días.

Los jesuitas exiliados también se interesaron en los sucesos políticos de su convulsionado tiempo. Seguían con frecuencia los acontecimientos que incluso comunicaban a sus amigos americanos, como el caso del P. Juárez, quien ponía al tanto de los hechos a los Funes en Córdoba.

Tan copiosa resultó la obra literaria de los jesuitas en el exilio que comenzaron a resurgir los bibliógrafos como el prolífero P. Raimundo Diosdado Caballero (Palma de Mallorca, 1740-Roma, 1829), quien también en el exilio publicó su biblioteca de escritores jesuitas entre 1814 y 1816. Su obra evidentemente tenía un correlato con la labor comenzada por Pedro de Ribadeneira (1602-1608), continuada por André Schott (1613), Philippe Alegambe (1643), Nathaniel Southwell (1676) y, sobre todo, Nicolás Antonio (1672-1696), del que los PP. Arévalo, Córdova y el mismo Rávago intentaron actualizar. Pero contemporáneo al P. Raimundo también se encontraba su maestro y amigo, el padre de la filología comparada, el jesuita Lorenzo Hervás y Panduro, que escribió sobre los escritores jesuitas del exilio, ubicados entre 1759 y 1799, obra que su autor no llegó a ver publicada y recién la editó Astorgano Abajo en 2007, indicando una treintena de escritores del Paraguay, de un total de 495 mencionados, es decir, 170 más que el propio Sommervogel. Indudablemente, el catálogo de Hervás es el más completo, superando no solo al francés sino también a Pólgar y al propio Aguilar Piñal, entre los más laboriosos, quienes excluyeron a gran cantidad de escritores jesuitas. En esta ocasión suprimimos de Hervás aquellos que escribieron pero murieron antes del exilio como Bartolomé de Mora y Francisco Bautista o Pedro Juan Andreu, que escribió en América, pero no sabemos si lo hizo en el destierro. Incluso el provincial Manuel de Vergara, que murió en el Puerto de Santa María en 1770. Sin pretender disminuir en lo más mínimo la inmensa obra de Hervás, señalamos apenas dos detalles como que el tal Francisco Larreta que fue nombrado provincial nunca estuvo en Paraguay y Rafael de Córdoba, que dice Hervás que fue visitador en el Paraguay, no lo fue.

Con su trabajo, el P. Raimundo dejó el camino abierto a los hermanos Agustín y Aloys De Backer, quienes se concentraron primero en las ediciones de Plantin con el objeto de actualizar los trabajos de los antiguos bibliógrafos, surgiendo la primera edición de sus siete volúmenes publicados entre 1853 y 1861. Se sumó a ellos y luego continuó la obra, el francés Carlos Sommervogel, quien anotó una serie de errores y, cuando uno de estos fue a París, se los entregó. De este modo, empezó a colaborar con ellos por correspondencia hasta la edición final de la obra, publicada en 12 tomos aparecidos entre 1890 y 1900.

Por otra parte, las obras de los exiliados también comenzaron a llamar la atención, por ejemplo, en el jesuita Alessandro Gallerani con prólogo de Salvador de Madariaga SJ (1897) y en especial referencia a los expulsos americanos, José Toribio Medina (1915). 
Finalmente, no podemos dejar de mencionar al P. José Eugenio Uriarte (Bilbao, 1842-Orduña, 1909), entusiasmado por abarcar la totalidad de la bibliografía jesuítica. La publicación de la obra de De Baecker-Sommervogel lo persuadió para limitarse a estudiar los escritores de la antigua Asistencia de España. Los primeros tres tomos los dedicó a anónimos y seudónimos (1904-1906), mientras que los cuatro y cinco fueron publicados por Enrique del Portillo y Mariano Lecina (19251935). Tiempo después se conoció su Biblioteca de Escritores de la Compañía de Jesús, obra trabajada con Lecinas, pero solo se publicaron dos volúmenes que llegan hasta la letra F. En la actualidad completa este trabajo el P. José Martínez de la Escalera SJ.

Ya el jesuita y bibliógrafo Antonio Possevino en el siglo XVI había catalogado siete grupos temáticos. Algunos años después su hermano de religión Claude Clément amplió a veinticuatro ${ }^{13}$. Pero es sumamente difícil la catalogación temática de autores, pues varios de ellos incursionaron en distintos temas y disciplinas. Nosotros simplemente y para organizar el texto dividimos el mismo en escritores extranjeros, españoles y criollos, con algún subtítulo ocasional. Trataremos los autores cuyas obras han sido escritas en el exilio, a los fines de acotar el tema, e intentaremos mencionar algunos textos que conocemos inéditos o perdidos.

\subsection{Autores extranjeros}

Como señalamos en un principio los jesuitas del norte de Europa tuvieron una particular visión del mundo americano, resaltando las culturas originarias y su propia experiencia misional. Sus exilios fueron atemperados pues no tuvieron que trasladarse a los Estados Pontificios, sino que regresaron a sus países. Uno de ellos fue Martín Dobrizhoffer (Frymburk, 1718-Viena, 1791), quien permaneció 18 años entre guaraníes, mocobíes y abipones. Deportado a Europa estuvo detenido en el convento franciscano de Cádiz hasta que pasó a Viena en 1773. Fue entonces que, a instancias de la emperatriz María Teresa, se publicó con gran repercusión su conocida obra en tres tomos, primeramente en alemán (1783-1784) (Fig. 1) y luego en latín (1784). También en inglés (1822-1935), aunque con omisiones y resúmenes de varios pasajes, y finalmente en castellano con traducción de Edmundo Wernicke y la introducción del P. Furlong (1967-1970), quien resalta la particular y exhaustiva descripción de esta etnia en toda su complejidad cultural. El autor no solo vuelca en sus palabras el profundo amor que les tuvo, sino que contagia al lector con su cálida lectura.

13. Sobre Possevino y la organización de las bibliotecas jesuíticas, ver AsTORGANO ABAJO, Antonio. "La Biblioteca jesuítico-española de Hervás y Panduro y su liderazgo sobre el resto de los ex jesuitas». Hispania Sacra, 2004, LVI, 113, pp. 170-268. 
Siguiendo con los extranjeros que estuvieron en el Paraguay, mencionemos al no menos conocido Tomás Falkner (Mánchester, 1707-Plowden-Hall, 1784), quien estudió física y matemáticas con Newton, siendo enviado a América por la Royal Society de Londres para estudiar las propiedades medicinales de plantas y aguas. Al llegar, no solo se hizo católico, sino que ingresó en la Compañía de Jesús, realizando múltiples actividades, entre ellas la exploración de la Patagonia donde incluso descubrió el primer fósil prehistórico. Regresó a su patria en 1771 incorporándose a la provincia jesuítica de Inglaterra. Su trabajo sobre la región austral de América fue extractado y publicado por William Combre en 1774 (Fig. 2). Al año siguiente la obra fue traducida e impresa en Alemania y luego en Francia en 1788. Simultáneamente a la aparición del libro, el oficial de la Secretaría del Consejo de Hacienda española don Manuel Machón la tradujo al castellano para alertar a Carlos III sobre este texto que afirmaba que era una clara incitación de los ingleses para invadir la Patagonia, que hasta entonces no había ocupado España. Desde ese momento la Corona se preocupó en arbitrar los medios para la ocupación y consideró a Falkner un traidor, como había sugerido Machón, además de prohibir la publicación en castellano. La no muy buena traducción de Machón recién la imprimió De Angelis en 1835, encontrándose otra mejor de la Universidad de La Plata, publicada en 1911. La obra tuvo gran repercusión e incluso fue utilizada por Darwin como guía preparatoria para su viaje en el Beagle. Otro trabajo menos difundido, y del que solo se conoce el ejemplar del British Museum, fue editado por Tomas Pennant en 1788, tiempo después del fallecimiento del autor. Falkner también escribió sobre la anatomía del cuerpo humano en dos tomos y varias otras obras menores que se han perdido y que bien el P. Furlong (1929 y 1954a) ha investigado. 
LA LITERATURA DE LOS JESUITAS EXPULSOS DE LA PROVINCIA DEL PARAGUAY. MEMORIAS DE UNA INTENSA LABOR

De la actual Polonia proviene el misionero Florián Paucke (Wiñsko, 1719-Neuhaus, 1779), quien para la hora de la expulsión trabajaba entre los mocobíes y de regreso a la Baja Silesia donó su famoso escrito al monasterio cisterciense de Zwettl en Austria. Su obra es conocida por sus alrededor de 150 notables ilustraciones que tienen su correlato temporal con la de su contemporáneo jesuita de México el bohemio Ignacio Tirsch. Estampa la memoria de los lugares, personajes, flora, fauna y acontecimientos que siguen el texto. Precisamente, los amenos relatos están llenos de detalladas informaciones sobre su llegada a América y regreso a Europa. Existen varias versiones reducidas ${ }^{14}$, tanto del texto como incluso de las ilustraciones, siendo la primera la del monje cisterciense Johannes Frast de 1829 (Fig. 3), concentrada en un extracto muy pequeño. Continuarán editando los jesuitas Andrés Kobler (1870), Agustín Brigmann (1908) y varias más. Pero fue el P. Furlong quien tuvo en sus manos el original y procuró su impresión castellana aparecida en tres tomos entre 1942 y 1944 con traducción del no menos meritorio Edmundo Wernicke. La edición introdujo varias ilustraciones coloreadas. La extensa obra de Paucke recién se publicó en su lengua en 1959 con reproducciones en color original, aunque el texto se vio alterado. Solo dos tomos, copiados de la edición argentina, fueron publicados en 1999 y 2000, hasta que se editó la obra completa en 2010, compuesta de las 141 ilustraciones que se han conservado, excepto unos borradores en lápiz, con un cd adjunto con los textos de la traducción de Wernicke.

14. Título original: Hin und Her. Hin süsse und vergnügt, her bitter und betrübt: das ist: Treu gegebene Nachricht durch einem im Jabre 1748 aus Europa in West-America, nabmentlich in die Provinz Paraguay abreisenden und im Jahre 1769 nach Europa zurukkebrenden Missionarium... Zwettler-Codex 420, volumen 2, Biblioteca del monasterio Cistirniense de Zwettl en Baja Austria. 


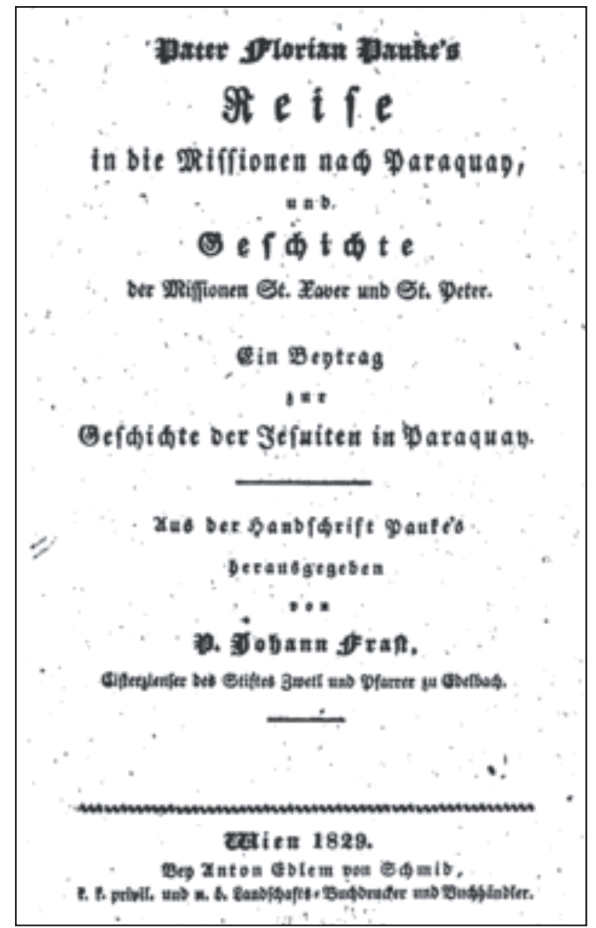

Fig. 3. Primera edición resumida del libro de Paucke (1829).

Otros autores extranjeros no descollaron tanto como los mencionados, pero además de ejercer sus ministerios se dedicaron a escribir. Tal es el caso del croata Nikola Plantich (Zagreb, 1719-Varaždin, 1777), quien para la expulsión se encontraba en el Colegio de Montevideo, llegando poco después a su patria; dejó escritas lecciones de lógica, predicaciones en lengua croata y la traducción en este último idioma de la gramática latina de Manuel Álvarez ${ }^{15}$. En el convento mercedario de Mendoza se encuentra una obra inédita sobre lógica, escrita en latín por Plantich ${ }^{16}$, seguramente redactada antes del exilio. Otro ejemplo fue el músico y matemático austríaco José Brigniel (Klagenfurt, 1699-Wiener Neustardt, 1773), quien llegó a Buenos Aires en 1729, siendo misionero entre guaraníes, abipones y guaycurúes, con quienes habitó hasta la expulsión que lo llevó a Italia por un corto tiempo. Escribió un vocabulario, gramática, catecismo y sermones en lengua abipona e inició un diccionario de la misma ${ }^{17}$. Sommervogel ${ }^{18}$ agrega que escribió una gramática, catecismo y sermones en guaraní. También el explorador, lingüista y misionero alemán Bernardo Havestadt (Colonia, 1714-Münster, 1781), llegado en 1747, escribió sobre la lengua araucana, editado en 1777 (Fig. 4) y reeditado en 1883, expresando que su mayor maestro fue su compatriota el P. Francisco Javier Wolfwisen.

15. Pobosna y Kratka za Vszaki Dan Meszecza Premishlyavanya, vszem szveto siveti y szrechno vumreti selyeechem kruto hasznovita. Zagreb, 1775 (SOMMERVOGEL SJ, Carlos. Bibliothèque de la Compagnie de Jésus. Nouvelle Édition. Tome VI. Bruxelles: Oscar Schepens y París: Alphonse Picard, 1895 , p. 876).

16. Binayan Carmona, Narciso. "Los primeros croatas en la Argentina». Studia Croatica, 1971, XII, 42-43, p. 124.

17. SIERRA, Vicente D. Los jesuitas germanos en la conquista espiritual de hispano-américa, siglos XVII y XVIII. Buenos Aires: Facultades de Filosofía y Teología de San Miguel e Institución Cultural Argentino-Germana, 1944, p. 299.

18. Sommervogel SJ, Carlos. Bibliothèque de la Compagnie de Jésus. Nouvelle Édition. Tome II. Bruxelles: Oscar Schepens y París: Alphonse Picard, 1891, p. 165. 


\subsection{Escritores españoles}

Indudablemente, los españoles fueron los más numerosos. Llegados a América desde distintas regiones en los diversos viajes que los procuradores en Europa hicieron en el siglo XVIII. Al referirnos a las actividades del esquema organizativo trasplantado en el exilio, mencionamos como protagonista al $\mathrm{P}$. Domingo Muriel (Tamames, 1718-Faenza, 1795 $)^{19}$. Desde que acató la orden de la supresión y aun antes ${ }^{20}$, se dedicó a escribir varias obras de distintas temáticas como el conocido Fasti Novi Orbis (1776) (Fig. 5), siendo una traducción aumentada de la obra del P. Charlevoix que trabajó el P. José Sans y que trata una síntesis cronológica sobre el descubrimiento y la colonización de América (1218-1771) ${ }^{21}$. También y con su conocido seudónimo de Ciriaco Morelli, recopiló 605 disposiciones pontificias sobre América. Como jurista destaca su libro Rudimenta Juris, que fue traducido al castellano con no mucha precisión en

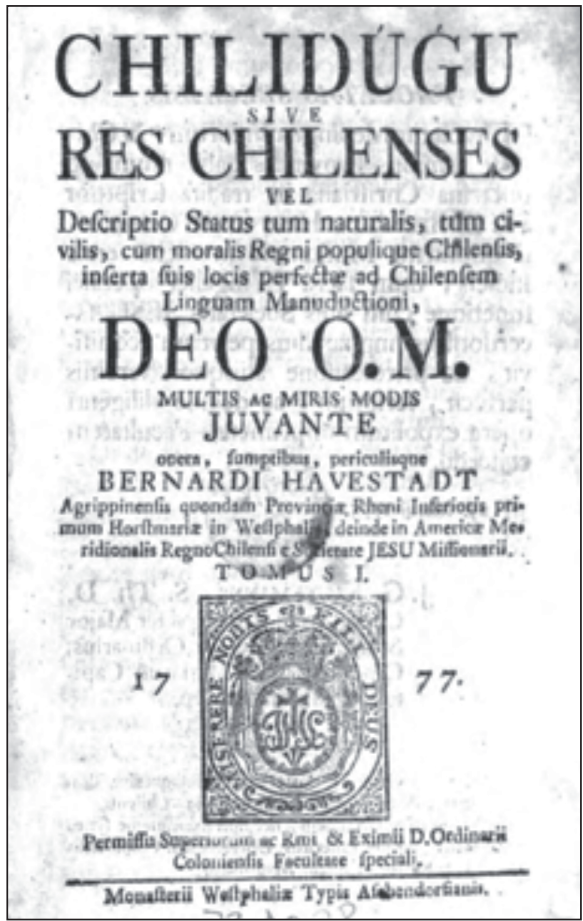

Fig. 4. Libro de Havestadt sobre la lengua araucana (1777). 1911, y el inédito titulado Jus nature et gentium apud Indios meridionalis, que se encuentra perdido. Obras históricas son la traducción al latín de la acreditada Historia del Paraguay del P. Charlevoix, en la

19. Sabemos de la existencia de dos retratos del P. Muriel. Uno publicado por primera vez en la oración fúnebre del jesuita Baltasar Masdeu impresa en Lugo en 1796, de quien el P. Miranda escribe del mismo: «bastantemente semejante», pues se hizo en base a una máscara mortuoria. Estampa que incluso circuló entre la gente que pretendía su canonización. El otro es un óleo aparentemente de mediados del siglo XIX que se encontraba en el Colegio del Salvador en Buenos Aires y se halla desaparecido.

20. Antes del exilio se conoce Lettre a l'auteur de l'article "Jesuite» dans le dictionnaire Encyclopédique (1766). Es una obra anónima, pero que reconoce su autoría Diosdado Caballero y que el P. Furlong halló un ejemplar en Valencia aunque sin la portada. Por otra parte, un manuscrito que permaneció inédito hasta que lo publicó el P. Furlong es la Breve noticia de las misiones vivas, escrita luego de su visita a las misiones de 1766 [FuRLONG SJ, Guillermo. Domingo Muriel y su relación con las misiones (1766). Buenos Aires: Librería del Plata, 1955c].

21. Fechas que aluden al descubrimiento de Groenlandia por los noruegos, por un lado, y al abandono de las islas Malvinas por parte de los españoles, por el otro. 
que no solo incorporó notas aclaratorias, sino que completó con varios capítulos ${ }^{22}$. Como autor ascético publicó en 1772 la Práctica de los Ejercicios, del P. Diertins (1698) y que la menciona Hervás y Panduro ${ }^{23}$, sumando la traducción de los Principios de la vida espiritual del P. Surin. También en la biografía del P. Miranda se incorporaron algunas cartas del P. Muriel, siendo la más importante la circular que envió exhortando a los jesuitas a seguir fieles a las normas de san Ignacio y una carta instructiva sobre los ministerios a celebrar, confesar y predicar ${ }^{24}$. Las obras de carácter teológico y apologéticas son Collectanae dogmatica (1792), que era el primer tomo de una enciclopedia filosófico-teológica que quedó inédita y perdida, y Opus contra Jansenianam ${ }^{25}$. También escribió una obra publicada contra los enciclopedistas franceses (1766) y otra inédita en defensa de la guerra guaranítica y contra los seguidores de Campomanes ${ }^{26}$. Otras de las tantas obras inéditas que hablan de su diversidad temática son la Cuestión compleja y la Demostración del estado de España ${ }^{27}$.

Seguimos con el excelente biógrafo de Muriel, el P. Francisco Javier Miranda (Ledesma, 1730-Bolonia, 1811), de quien se conservan varios escritos y precisamente la biografía de su maestro es el segundo texto suyo que llegó a publicarse, aunque mucho después de su muerte. Efectivamente el manuscrito fue recuperado por los jesuitas en Roma y custodiado por los de Barcelona, hasta que el P. Hernández lo hizo conocer. Es uno de los textos del género biográfico más amenos y llenos de información escrito por los antiguos jesuitas, pero con el objeto de contribuir a la causa de beatificación de Muriel. Su primera obra, aparecida una década antes, fue impresa en varias entregas de una publicación periódica, relatando los avatares de la partida de los novicios de Córdoba (1906). Pero un trabajo que lo destacará es indudablemente El Fiscal Fiscalizado, que recién fue

22. Fue publicada en 1779 y traducida al castellano por el P. Hernández en siete tomos aparecidos entre 1910 y 1919.

23. Hervás y PANDURo, Lorenzo. Biblioteca... Op. cit., p. 401.

24. Miranda SJ, Francisco Javier. Vida del Venerable... Op. cit., pp. 493-524 y 525-542. De la primera hay copia del texto en el AL: Ilustres 20/12 Carta del P. Domingo Muriel, Provincial de la Provincia del Paraguay a sus súbditos sobre el modo de conservar el espíritu religioso, extinguida la Compañia de Jesús, escrita antes que lo fuese.

25. El P. Furlong sigue al P. Miranda en cuanto que fue una frustrada impresión que el P. Muriel presentó para su aprobación en el Tribunal de la Inquisición de Faenza en 1783 con el título Monumenta bistorica..., que venía a ser una continuación de la obra de Lafitau contra los jansenistas (Furlong SJ, Guillermo. Domingo Muriel... Op. cit., p. 80).

26. El manuscrito Recurso de la Provincia del Paraguay de la Compañía de Jesús del Tribunal de la Verdad, y de la inocencia, en causa de la execucion, y resultas del Tratado de Limites entre España y Portugal (ARSI, Paraq. III, ff. 203-230) con una síntesis publicada por Charlevoix; y Entretenimiento sobre la consulta del consejo extraordinario al Rey Don Carlos Tercero acerca de lo que se había de responder al Breve del Papa Clemente XIII, manuscrito que cita Miranda pero se encuentra perdido (Miranda SJ, Francisco Javier. Vida del Venerable... Op. cit., p. 440).

27. Furlong SJ, Guillemo. Francisco Miranda y su sinopsis (1772). Buenos Aires: Ed. Theoria, 1963 , p. 29 


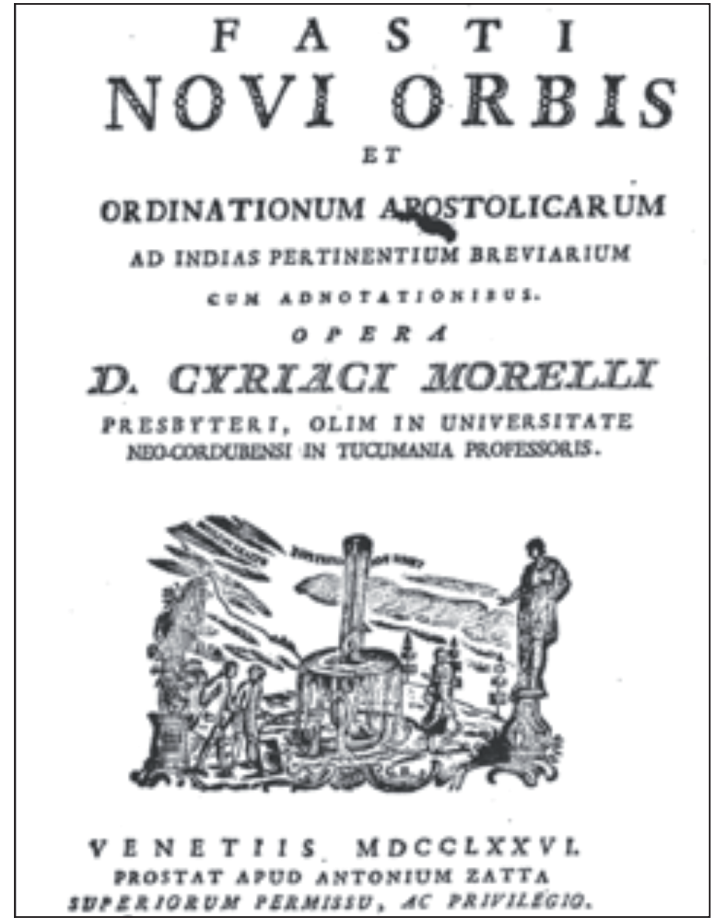

Fig. 5. El Fasti Novi Orbis de Muriel con el seudónimo de Morelli (1776). impreso en 2013, y donde el P. Miranda intenta demostrar que Campomanes estaba al frente de una conspiración compuesta por jansenistas, francmasones y filósofos libertinos que pretendían acabar con los jesuitas. No obstante, la obra trae gran cantidad de tópicos americanos. Otro libro también recientemente impreso es El Perro de Diógenes (2010), donde el P. Miranda critica conductas individuales y colectivas a través de un relato de profunda erudición en el campo de las humanidades. El P. Furlong $^{28}$, al biografiar al P. Miranda, publicó Sinopsis o Ensayo de los daños en lo espiritual y temporal seguidos del destierro, además de mencionar una gran cantidad de obras inéditas conservadas en su mayoría en los archivos de Loyola en Azpeitia y Toledo en Alcalá de Henares.

Pero si de biógrafos tratamos, destaquemos al humanista catalán José Manuel Peramás (Mataró, 1732-Faenza, 1793). Después de haber publicado la vida de Ignacio Duarte y Quirós en la imprenta de Córdoba, en el exilio incursionó en la poesía, escribiendo un poema en tres partes y 2.100 versos sobre el descubrimiento de América, publicado en 1777, y otro laudatorio dedicado al obispo de Faenza Domingo Marchioni Mancifforte en 1787. Como mencionamos, cultivó el género biográfico con gran éxito, publicando primero la vida de seis jesuitas en $1791^{29}$ y luego de otros trece, en $1793^{30}$ (Fig. 6). En este último incluyó la biografía del notable novicio Baigorri,

28. Furlong SJ, Guillemo. Francisco Miranda... Op. cit., pp. 57-92.

29. Contamos con una reedición impresa en 1946 con la traducción de Antonio Ballus y prólogo de Guillermo Furlong. Los seis biografiados son los PP. Manuel Vergara, Manuel Querini, Pedro Juan Andreu, Juan Escandón, Vicente Sans y Segismundo Griera.

30. Incluye las biografías de los PP. Ignacio Morro, Juan Mesner, Juan Suárez, Ignacio Chomé, Francisco Ruiz de Villegas, Juan Ángel Amilaga, Antonio del Castillo, Esteban Pallozzi, Clemente Baigorri, Francisco Urrejola, Joaquín Irribarren, Cosme Agullo y Martin Schmid. Esta segunda serie de biografías, Peramás no llegó a verlas impresas debido a su muerte en Faenza en ese mismo año. 


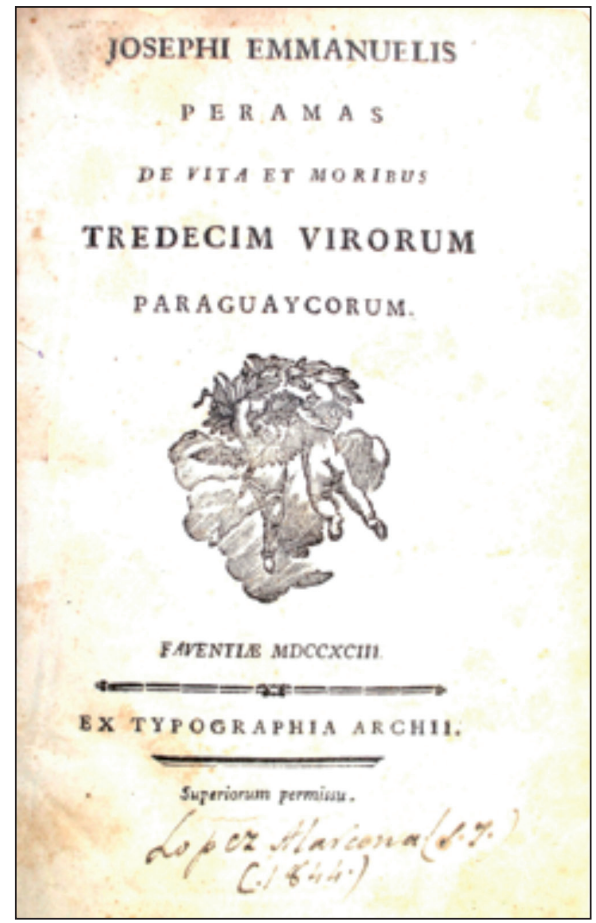

Fig. 6. Primera edición de las 13 biografías de Peramás (1793). que se tradujo primero al italiano en el año $1859^{31}$ y al español en Barcelona en $1895^{32}$. Esta vez incluía no solo trece personajes, sino una primera parte, donde comparaba las reducciones guaraníticas con la doctrina utópica de la República de Platón ${ }^{33}$.

De Peramás merece especial mención el muy detallado diario del exilio que no solo fue conocido por sus contemporáneos, sino que incluso fue censurado. Del original se conservaron dos versiones, una en castellano y otra en latín un poco más extensa. Esta última fue impresa en italiano por el historiador José Boero en 185934. Finalmente, la versión castellana fue publicada por primera vez en una serie de entregas, aparecidas entre 1906 y 1907 en la Revista Eclesiástica del Arzobispado de Buenos Aires. Pero fue el padre Furlong quien en 1937 se ocupó extensamente de la biografía del autor del texto y en 1952 le agregará el diario, con lo que inició la famosa y monumental serie de Escritores Coloniales Rioplatenses. Reciente-

mente, ha vuelto la atención historiográfica tanto sobre la figura de Peramás como en particular de su diario y descripción de la provincia jesuítica. Aunque muchos

31. El P. Giuseppe Boero (1814-1884) al revisar los cuatro tomos del menologio de Patrignani publicado en 1730 y ampliar en dos tomos, publicando todo en 1859, incorporó tres biografías de Peramás, la del P. Juan de Escandón en el tomo uno (pp. 145-153), la del P. Juan Pedro Andreu en el tomo dos (pp. 436-447) y la de Clemente Baigorri en el tomo uno (pp. 438-444).

32. Revista Popular. Semanario Ilustrado. Barcelona: Librería y Tipografía Católica, 1895, Año 39, pp. 86-88. Poco después el jesuita Vicente Agustí (1849-1915) la publicó en un folleto de 16 páginas, también en Barcelona, agregándole un adecuado subtítulo. Finalmente, la biografía de Peramás fue nuevamente traducida en 1999 por Italo M. Viotto.

33. De administratione guaranitica comparate ad rempublicam Platones commenterii fue reeditada con traducción al castellano de Juan Cortés del Pino en 1946 y luego por Francisco Fernández Pertiñez y Bartolomé Meliá en 2004 a través del Centro de Estudios Paraguayos "Antonio Guasch" de Asunción del Paraguay.

34. En 1868 el P. Augusto Carayón la tradujo y publicó en francés. También apareció la traducción inglesa en Londres en 1875, y en lengua alemana, cuya edición estuvo a cargo de Antonio Huonder, aparecida entre 1899-1900. 
de sus escritos todavía permanecen inéditos y ya fueron mencionados por Hervás y Panduro ${ }^{35}$ en su tiempo.

También escribieron del exilio Bernardo de Castro (La Rioja, Arg. 1729-Faenza, 1781), cuyo dramático viaje comienza en la reducción de San José de vilelas, a quien a su vez se le debe un muy interesante manuscrito sobre esta etnia de Salta escrito en $1771^{36}$. Se suman Juan Bautista Roca (Palma de Mallorca, 1725-Civitavecchia, 1800), que escribió desde el colegio de Belén en Buenos Aires, además de los aquí mencionados PP. Iturri, Sánchez Labrador, Paucke, Juárez y Miranda. Obras que como señalamos en otro pasaje fueron recientemente compiladas. De ellos destaquemos al catalán José Pellejà (Riudoms, 1730-Rávena, 1787), quien no solo escribió una relación de la expulsión desde chiquitos, sino que Hervás mencionó tres obras de su autoría: una gramática en lengua chiquita que según Camaño lo escribió de memoria, siendo posiblemente la que encontró Sieglinde Falkinger en la biblioteca Estense Universitaria de Módena. Otras obras que menciona el polígrafo jesuita son un Diccionario de varias materias y secretos de artes mecánicas y una Instrucción para ayudar a morir bien.

El notable literato Joaquín Millás (Zaragoza, 1746-1811), que llegó a Buenos Aires en 1764, se desempeñó en el exilio como catedrático de Metafísica en el colegio Real de San Pedro en Plasencia (Italia). Psicologista, aunque más inclinado como Arteaga a la escuela escocesa que a los postulados de Condillac, para él la observación del hombre era el fundamento de la filosofía sin tener reparo en aceptar la duda cartesiana y patrocinar el método analítico ${ }^{37}$. Desde Mantua escribió su conocido ensayo sobre el paralelo de los tres géneros de la poesía de Virgilio con la poesía italiana y la relación con las demás artes (1785). Bien recibida la obra por los eruditos de su tiempo y con la ayuda de José Nicolás de Azara, ministro de Carlos III, publicó también en Mantua su segunda obra en dos tomos en 1786 y un tercero en 1788, que versa sobre el verdadero fin de la cultura humana (Fig. 7). También esta obra fue bien recibida, incluso el jesuita y literato italiano Jerónimo Tiraboschi incluyó un extracto de la misma en los Jornales de Módena. Al llegar el libro a España fue elogiado por el conde de Floridablanca, por lo que Carlos III dobló su pensión. Fue entonces que Millás enfermó y debió mudarse a un pueblito en las afueras de Bolonia, pero por poco tiempo ya que fue llamado a la mencionada cátedra de Plasencia. Allí estuvo dos años y regresó a Zaragoza no sin antes publicar su introducción a la metafísica (1798), en dos tomos dedicados a sus discípulos, y donde contempla tratados de lógica, ontología, cosmología, psicología y teología moral. De las obras hasta aquí reseñadas se ocupó extensa

35. Hervás y PANDURO, Lorenzo. Biblioteca... Op. cit., p. 437.

36. El original de 48 folios se conserva en el ARXIU con copia en AL y publicado por Guillermo Furlong en 1939.

37. MEnÉndez y Pelayo, Marcelino. Historia de las ideas estéticas en España. Madrid: CSIC, v. 1, 1993, p. 1151 
y detalladamente Latassa y Ortín ${ }^{38}$, el mayor de los bibliógrafos de las letras aragonesas. Aunque no incluye del jesuita Millás otras obras publicadas en Italia, más precisamente las de Verona y Plasencia de 1797 , que no hacen más que reafirmar su vocación ecléctica y su gusto por el racionalismo de Descartes y el método analítico.

El moralista aragonés Juan Francisco Aznar (Palomar, Teruel, 1743-Zaragoza, 1800), llegó a Buenos Aires a mediados de 1764 y la expulsión lo sorprendió mientras estudiaba en Córdoba. En Italia residió en Ferrara hasta que pudo regresar a España a la casa de un tío en Huesca. Falleció fortuitamente en un viaje a Zaragoza. Dos obras se conocen de este autor. La primera, impresa en Ferrara en 1786 (Fig. 8), fue traducida y enviada a España para su consideración, pero el propio P. Luengo se refiere al poco mérito de la misma ${ }^{39}$. Su segundo trabajo impreso en 1791 también en Ferrara fue una traducción al italiano de un libro del arzobispo de Toledo Valerio e Lossa.

Por último, hubo varios jesuitas que se dedicaron a traducir obras de otros autores, como los mencionados Aznar y Muriel, pero también se abocó a esta tarea Manuel Sierra (Argamasilla, 1725-Faenza, 1790), quien ingresó a la Compañía de Jesús de la provincia de Castilla en 1742 y tres años después ya se encontraba en Buenos Aires. Según Hervás tradujo al español la obra del jesuita Crasset sobre la devoción a la Virgen María. Otro que se abocó casi exclusivamente a las traducciones fue el moralista y misionero Manuel García (Reiteños, 1715-Faenza, 1782), quien había arribado a Buenos Aires en 1743 y para la expulsión se encontraba en Santa Fe. Tradujo una obra ascética y otra mística del jesuita Juan Bautista Scaramelli publicada en Madrid por el P. Peramás en 1790 y otras obras que quedaron

38. LATASSA Y ORTÍN, Félix de. Biblioteca nueva de los escritores aragoneses que florecieron desde el año de 1795 hasta el de 1802. Pamplona: Oficina de Joaquín de Domingo, t. VI, 1802, pp. 126-155.

39. Hervás y PANDuro, Lorenzo. Biblioteca... Op. cit., p. 129. 


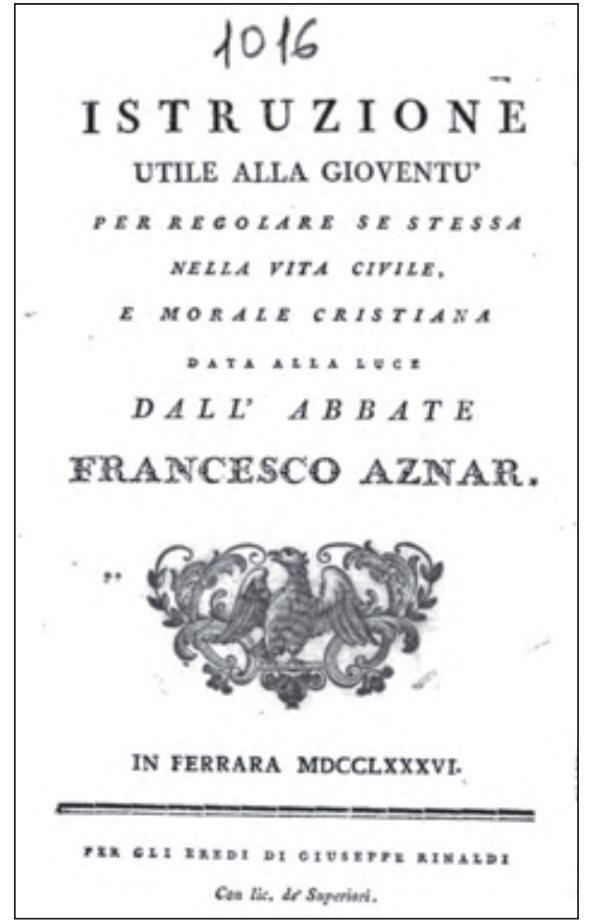

Fig. 8. Una de las obras de Aznar publicadas en Ferrara (1786).

inéditas del jesuita Diego Álvarez de Paz, el franciscano Antonio Arbiol y varias de monseñor Alfonso Ligori $^{40}$. Además, compuso una historia del colegio de Santa Fe, donde fue su último rector ${ }^{41}$. También en esta actividad se encontraba el lingüista e historiador Nicolás Lagua (Haro, 1740-Poggio Mirteto, 1794), quien llegó a Buenos Aires en 1764 y pasó a estudiar en Córdoba, donde fue arrestado. En Faenza obtuvo el sacerdocio, dedicándose a la enseñanza de los hijos del marqués de Muti Papazurri, pero por razones de salud se trasladó a la provincia de Sabina en 1790, siendo párroco de la iglesia de Poggio Mirteto. De su experiencia como maestro de Girolamo y Pompeo, hijos del marqués, publicó en 1788 una obra. Aunque no fue la única, ya que Hervás señala otras dos, positivamente reseñadas por Luengo y publicadas en 1789 y 1790 (Fig. 9), además de la traducción de un escrito del sacerdote Blas Ortiz, fallecido en 1540, y una traducción al italiano de un libro del obispo san Alberto de 1792 y los dos primeros tomos de las Letras Pastorales del mismo prelado, impreso en Roma en 1793, cuyo original español apareció en Madrid en 1786.

2. LOS ESCRITORES DE LA MALOGRADA EXPEDICIÓN DE LOS PP. ROBLES Y MURIEL

Fueron ochenta hombres los autorizados para la última expedición al Paraguay. Pero los procuradores Muriel y Robles alcanzaron a despachar una primera tanda de veinte ${ }^{42}$ que zarparon de Cádiz el 11 de enero. Cuando se aprestaron a

40. Hervás y Panduro, Lorenzo. Biblioteca... Op. cit., pp. 244-245.

41. Furlong SJ, Guillermo. Diego León Villafañe y su "Batalla de Tucumán" (1812). Buenos Aires: Ediciones Theoría, 1962, p. 478.

42. La lista de 18 sacerdotes y 2 coadjutores en PASTELLS SJ, Pablo y MATEOS SJ, Francisco. Historia de la Compañía de Jesús de la Provincia del Paraguay, t. VIII, segunda parte 1760-1768. Madrid: Consejo Superior de Investigaciones Científicas, 1949, pp. 1200-1201. 
embarcar a los restantes, el fiscal del Consejo adujo que eran muy jóvenes y solo autorizó a cuatro.

Los jesuitas reclutados para el Paraguay llegaron a Montevideo el 25 de julio de 1767 y al día siguiente regresaron sin siquiera pisar tierra rioplatense. Entre ellos se encontraba el por entonces estudiante zaragozano, que prestigió su nombre como matemático, Manuel Gervasio Gil (Villarroya, 1745-Piacenza, 1807). Fue vindicador y defensor de las teorías del matemático y filósofo jesuita Rudjer Boscowich y para ello publicó una obra en Foligno en 1791, dedicado a Alexandre Pianciani y mencionada por Hervás. Aunque no cita otras dos aparecidas en Piacenza entre 1798 y 1799.

Por su parte, el lingüista José Sans (Borjas del Campo, 1734-Roma, 1804) fue del grupo que no llegó a embarcar, pero quedaron a su cargo los enviados a Italia. En ese viaje profesó su cuarto voto en Córcega.

El tarraconense ya había publicado un libro antes del exilio; pero en Faenza, cuenta el P. Luengo que "escribió por lo menos un librito", titulado Qui sunt hostes (Fig. 10), que no menciona Hervás y salió impreso en 1792. Cuando seis años después emprendió el viaje de regreso a España, su barco naufragó y perdió muchos de sus papeles, incluyendo manuscritos del P. Muriel, de quien había sido amigo y confesor. En 1774 apareció una obra considerada de su autoría aunque sin el nombre del autor. A los dos años se publicaron dos trabajos, uno dividido en dos partes escrito en versos sexámetros y los Fasti novis orvis editado por Muriel. Según Hervás las próximas obras se publicaron en 1784 y 1787 . Finalmente, se imprimió en Faenza en 1792 un trabajo contra los filósofos ilustrados, dedicado al obispo de Faenza marqués de Manciforte, reseñado con satisfacción por el P. Luengo y otros críticos como Cernitori. Luego de un estudio preliminar donde expone que Dios es autor de paz y no de sedición, y que no son personas de Cristo aquellas que causan perturbaciones, pasa a la primera parte de tres capítulos en la que explica cómo hay que tratar con los que están en el error a causa de sus prejuicios, de cómo se conoce al hombre rector por sus obras y de cómo el apóstol Pablo nos enseña ese camino. La segunda parte consta de 16 capítulos continuando con 


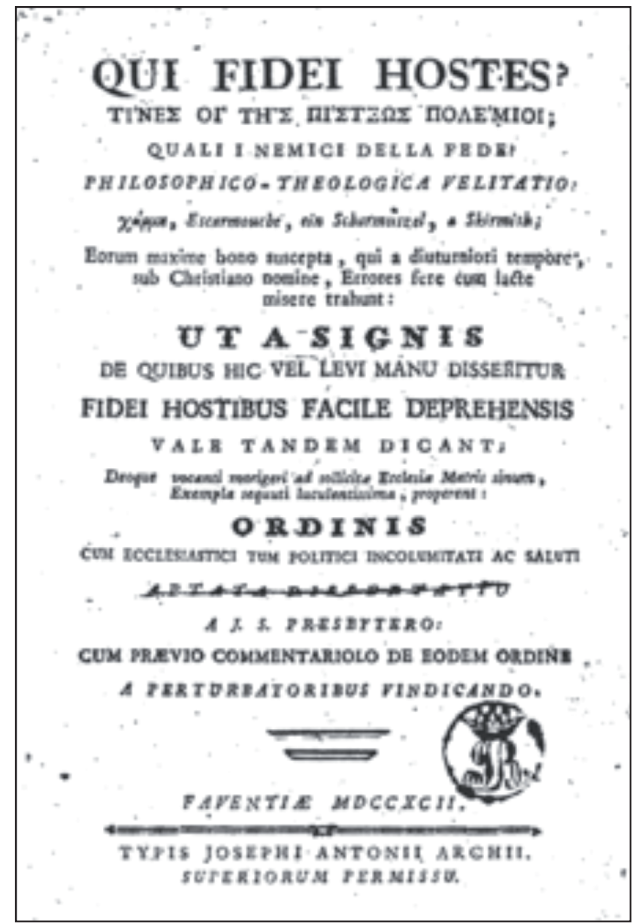

Fig. 10. Qui sunt hostes... del P. Sans (1792).

los mismos asuntos que involucran la doctrina relativa a las relaciones entre la Iglesia y el Estado. Furlong ${ }^{43}$ le adjudica a Sans, por su carácter y espíritu, la obra Dammatio et probibitio de 1786 que se encuentra entre los papeles del P. Luengo.

Otro jesuita que acompañó al P. Sans fue José Antonio Serrano (Huéneja, 1740-Génova, 1826). Después de los largos años de exilio en Parma y Lugo, regresó a España en 1798 residiendo en Barcelona hasta 1801 que volvió a Italia. Sus obras son muy difíciles de hallar, comentadas desde Hervás y Panduro ${ }^{44}$ hasta Furlong ${ }^{45}$. La única reseñada en forma completa es la que ataca el famoso trabajo de Spedalieri sobre los derechos del hombre defendiendo el poder divino de los reyes publicada en 1792 . Otra es Planeticoli, que en su primera edición (1797) estampa su seudónimo de "Antonio Sornera" y recién se ubica el suyo en al menos dos ediciones posteriores (1800 y 1805). Otros dos trabajos ni siquiera fueron hallados por su biógrafo, uno sobre unas conclusiones de física (1802) y otro un discurso pronunciado en Piacenza sobre los terremotos (1806). Según Furlong en 1813 publicó su mejor trabajo referido a los astros opacos y luminosos.

Finalmente, Julián Nieto (Orgaz, 1748-Génova, 1784) ingresó a la Compañía de Jesús en 1763, pero recién se pudo embarcar en la expedición de los PP. Robles y Muriel en la fragata Santa Brígida o Venus que regresó con otros muchos jesuitas. De España pasó a los Estados Pontificios. Su aparentemente única obra la cita Hervás y la localizamos en la Biblioteca Manfrediana de Faenza, siendo editada en 1776.

43. Furlong SJ, Guillermo. "Vicente Sans y José Sans». Estudios, Buenos Aires, 1945b, 397, p. 256.

44. Hervás y PANDURO, Lorenzo. Biblioteca... Op. cit., p. 671.

45. Furlong SJ, Guillermo. Matemáticos argentinos durante la dominación hispánica. Buenos Aires: Editorial Huarpes, 1945a, p. 133. 


\section{ESPAÑOLES ABOCADOS A LA CIENCIA Y A LAS CULTURAS ORIGINARIAS}

El marino y matemático José Quiroga (Fabal, 1707-Bolonia, 1784) llegó a Buenos Aires en 1745 e inmediatamente junto con los PP. Cardiel y Strobel participó en la expedición a la Patagonia. Dos escritos redactados en el Paraguay, referidos a sus expediciones, fueron publicados en el siglo XIX. En su exilio residió en Bolonia con el astrónomo Ignacio Frías. Nos interesa su labor en este período, por tanto, mencionaremos solo un tratado de escaso valor, pero que demuestra su interés por las matemáticas y la navegación, publicado en 1784 (Fig. 11). Si bien la portada establece a Méndez como autor, él mismo lo aclara en la introducción expresando que su tío el P. Quiroga le regaló el texto.

Una gran y conocida figura fue José Cardiel (Villa de la Guardia, 1704-Faenza, 1781), que llegó a Buenos Aires en 1729. Fue un notable y popular misionero que junto con los PP. Quiroga y Strobel recorrieron las costas patagónicas. La expulsión lo llevó de las reducciones guaraníticas rumbo a Faenza donde se dedicó a componer algunos mapas publicados por el P. Furlong y a reelaborar sus textos sobre los guaraníes. Solo pudo ver impresa una breve relación titulada $D e$ moribus guraniorum, y con tan solo sus iniciales que publicó el P. Muriel al traducir al latín y completar la obra de Charlevoix. El tema de las misiones fue una constante entre sus escritos y que tuvieron su inicio en la carta que le escribió a su maestro el P. Pedro Calatayud en 1747, publicada por el P. Furlong (1953). Igual tema lo redacta en el exilio, solo que sin el asombro y visión juvenil de aquellos primeros años. Incluso lo hizo al mismo destinatario a fines de 1770 y principios del siguiente en que se publicó en Faenza. Muchos años después fue incluida en el libro del P. Hernández de 1913 y en 1994. En el exilio también escribió un compendio de la historia paraguaya (1780) con el seudónimo de presbítero "José Dorceli», publicado en 1984, después que el manuscrito fuera hallado en una biblioteca de Bologna.

José Jolis (San Pedro de Torrelló, 1728-Bolonia, 1790) llegó a Buenos Aires en 1755 y terminó sus estudios en Córdoba para luego ser enviado al

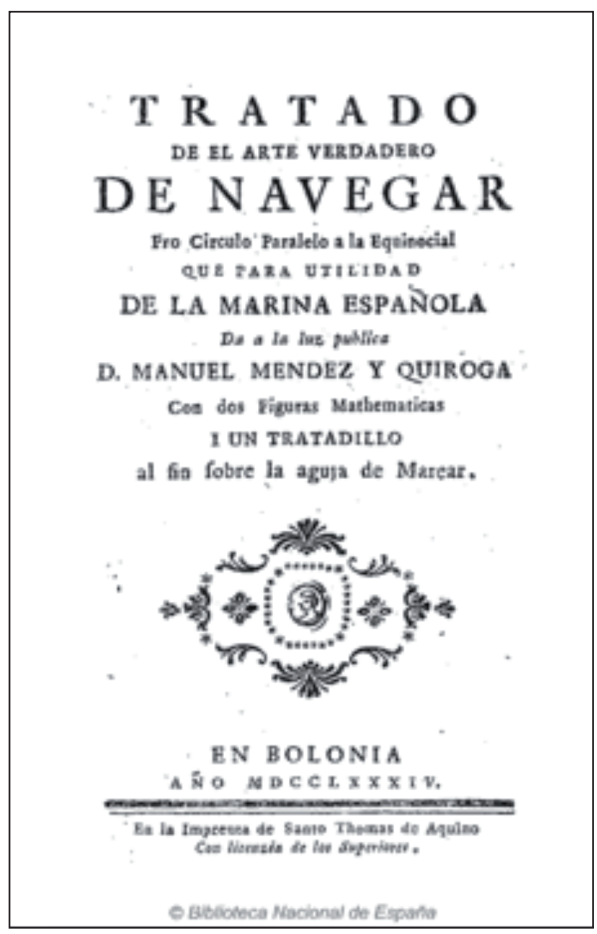

Fig. 11. La poco conocida obra de Quiroga publicada en Bolonia (1784). 
Chaco. Después de la expulsión y establecido en Faenza, publicó en 1789 parte de su obra consagrada a la historia natural de aquella región que permanecía en su recuerdo imborrable (Fig. 12). Tenía preparados otros tres tomos cuando le sobrevino la muerte al año siguiente y su trabajo quedó extraviado. En 1972 María Teresa Acuña tradujo la obra con introducción de Ernesto Maeder.

Es verdaderamente enciclopédica la obra del manchego José Sánchez Labrador (La Guardia, 1717-Rávena, 1798), quien desde su estadía en Italia compuso varios volúmenes referidos a la botánica, zoología, lingüística, geografía, etnografía e historia del Paraguay. Sabemos que al

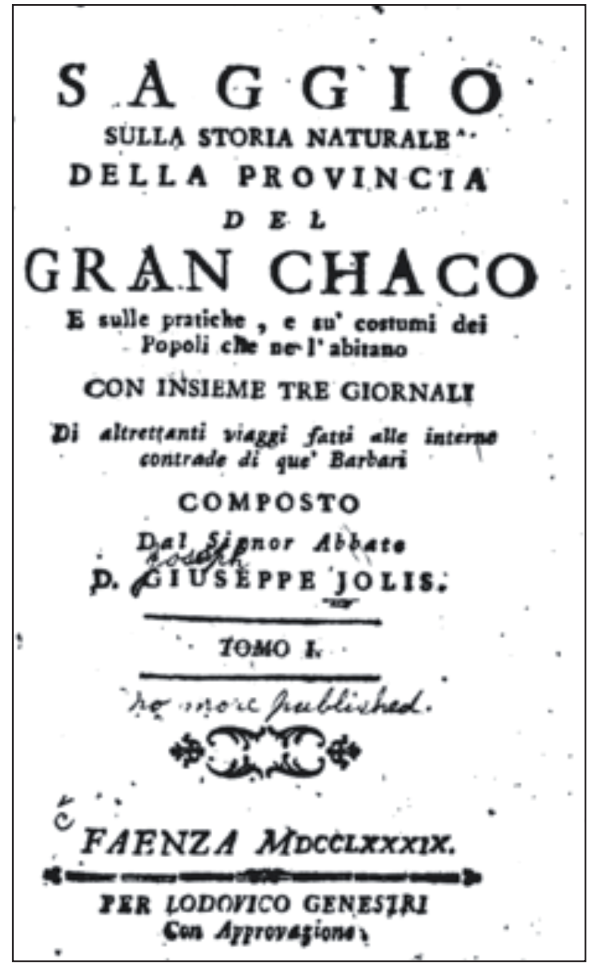

Fig. 12. La conocida obra de Jolís publicada en Faenza (1789). ser arrestado se le incautaron diversos papeles que pretendía llevar a Europa, aunque no es seguro si realmente cargó con ellos. Pero resulta inverosímil que tanta información volcada en sus investigaciones en el exilio fuera guardada en sus recuerdos. José Sánchez Labrador residía en Rávena donde era rector del colegio jesuítico ${ }^{46}$. No consignamos el número de volúmenes, pues en realidad nadie los ha visto en su conjunto. Solo se publicaron tres tomos del Paraguay Católico, entre 1910 y 1917, mientras que el manuscrito del ARSI, sobre el Paraguay Natural Ilustrado, acaba de ser publicado ${ }^{47}$, que se suma al de la lengua eyiguayegi publicado por Susnik (1971). Otra gran parte de otros manuscritos firmados en Rávena entre 1769 y 1776 se conservan dispersos en archivos europeos, correspondientes al Paraguay Católico en la RAH y en el AHPT. Los tomos del Paraguay Cultivado se encuentran perdidos y son innumerables las publicaciones parciales de la obra en general y que bien se ocuparon sus últimos biógrafo ${ }^{48}$.

46. MIRANDA SJ, Francisco Javier. Vida del Venerable... Op. cit., p. 350.

47. Deckmann Fleck, Eliane Cristina. As artes de curar em um manuscrito jesuítico inédito do Setecentos. São Leopoldo: Editora Unisinos, 2015.

48. SAINZ Ollero, Héctor et al. José Sánchez Labrador y los naturistas jesuitas del Río de la Plata. La aportación de los misioneros jesuitas del siglo XVIII... a través de la obra de José Sánchez Labrador. Madrid: Ministerio de Obras Públicas y Urbanismo, Centro de Publicaciones, 1999. 
Juan Ambrosio Fernández (Paredes de Nava, 1745-Valencia, 1820) llegó a Buenos Aires en 1764 y fue arrestado en Córdoba. Pasó a Nápoles en 1805 para incorporarse a la Compañía de Jesús restaurada y luego de expulsados de allí por José Bonaparte, se trasladó a Palermo donde trabajó en su biblioteca pública. Hervás menciona un "Calendario político-astronómico, y algunos folios volantes" de su autoría, pero que no hemos localizado.

Otro que descolló por sus estudios originales fue el misionero y naturalista Ramón María de Termeyer (Cádiz, 1737-1814), hijo de alemanes, llegó a Buenos Aires en 1764 y la expulsión lo sorprendió en la reducción de San Javier de mocobíes. Trasladado a su exilio en Italia residió en Génova, Faenza y Milán, donde trabajó intensamente publicando varias investigaciones que le valieron la incorporación a la Academia Real Agraria de Turín y un premio de la Sociedad Patriótica de Milán. Aunque en forma incompleta, sus escritos fueron reseñados por Hervás, Baecker y Sommervogel, y ordenados por Ramón de Santa María en 1907. Publicó en las revistas Scelta di opuscoli interessanti, de Milán; Raccolta ferrarese di opuscoli scientifici, e letterari, de Venecia, y Opusculi scelti sulle scienze e sulle arti, también de Milán. Una compilación de siete artículos fue remitida por el comisario Greco a Azara en $1787^{49}$. Escribió sobre sus experiencias con el gusano de seda, el veneno de las víboras, insectos marinos, diversos coleópteros y sobre la excelencia de la yerba. Pero fundamentalmente fueron auspiciosos sus aportes al cultivo de la tela de araña para hilar telas, confeccionando incluso un par de medias que envió a Carlos III y a otros monarcas. Con su colección de insectos formó un museo en su propia casa, pero el bombardeo a Milán por

49. SANTA MARÍA, Ramón de Santa María. "El naturalista Termeyer (noticias biográficas)». En Lineo en España. Homenaje á Linneo en su segundo centenario (1707-1907). Zaragoza: Sociedad Aragonesa de Ciencias Naturales, 1907, p. 204. 
parte de las tropas francesas en 1796 destruyó su morada y sus insectos se esparcieron. De su labor como principal investigador de la seda arácnea destaquemos un tomo entero de 425 páginas que dedicó a demostrar que la tela de las arañas era superior a la de los gusanos (Fig. 13). Esta publicación es la primera de una serie con un total de cinco volúmenes con la misma portada. Los tomos segundo y tercero, publicados en 1808, tratan sobre la lana, destacando la de los guanacos de América. El tomo cuarto, publicado en 1809, contiene varios artículos sobre su especialidad y, finalmente, el quinto, publicado en el mismo año, lo dedicó casi íntegramente a las misiones guaraníticas. Una selección de sus trabajos fue traducida al inglés y publicada por el viajero Alexander Caldcleugh (1795-1858) en 1825 (Furlong, 1948).

Varios jesuitas no solo trabajaron entre los guaraníes, sino también con los vilelas y dejaron sus impresiones. Pues tanto ellos, como los mocobíes, abipones y otros, constituían la nueva esperanza evangelizadora en el Paraguay. Uno de ellos fue el meritorio misionero e historiador Tomás Borrego (Écija, 1728-Faenza, 1790), quien llegó al Río de la Plata en 1749 siendo arrestado en la reducción de San Juan Bautista de isitines en Salta. Residió en Faenza y luego Roma, aunque posteriormente regresó y la Secretaría de Indias le encargó una obra histórica desde la Era Cristiana en 13 tomos que concluyó en 1788 y al año siguiente los 3 tomos del índice. La obra recorrió varios despachos hasta que finalmente quedó inédita. El largo título, que comienza con El mundo cristiano y político..., lo reseña Hervás y Panduro ${ }^{50}$. También se conserva una relación de los indios vilelas, pues fue misionero en la reducción de San Juan de Valbuena de Petacas por muchos años, es un informe solicitado por Camaño que se encuentra en ARXIU.

También el P. Furlong al escribir sobre los vilelas publicó varios escritos del mencionado P. Castro y del catalán Antonio Moxi (Berga, 1722-Rávena, 1791). Este último llegó a Buenos Aires en 1745 y fue misionero entre los chunupíes y omoampas, escribiendo una relación que publicó el P. Furlong (1931).

Entre los otros que trabajaron con los vilelas se encuentra el español Alonso Sánchez (Siruela, 1723-Faenza, 1773), de quien expresa el P. Furlong ${ }^{51}$ que una relación suya sobre el Chaco ha llegado hasta nosotros en copia que hizo Cardiel. Con los vilelas también trabajó el P. Olcina, a quien el P. Furlong llama erróneamente con el nombre de su hermano Vicente. El alicantino Luis Tomás Olcina (Gorga, 1733-Ferrara, 1777) llegó a las costas del Plata en 1755, habiendo sido arrestado en la reducción de San Juan Bautista de isistines del Chaco poco después que profesara su cuarto voto. Residió en Faenza, luego en Rávena y en

50. Hervás y PANDuro, Lorenzo. Biblioteca... Op. cit., pp. 578-579. Los manuscritos, aunque no completos, se encuentran en la biblioteca de la Real Academia de Ciencias Morales y Políticas de Madrid (MENÉndez y PELAYo, Marcelino. Historia... Op. cit., p. 216).

51. Furlong SJ, Guillermo. Entre los Vilelas de Salta. Buenos Aires: Academia Literaria del Plata, 1939, p. 44 
Ferrara desde 1773 junto con su hermano Vicente, su primer biógrafo ${ }^{52}$. En Rávena tradujo la célebre comedia francesa La Dame Docteure y escribió una obra sobre recuerdos, flora y fauna del Chaco, publicada como anónima por Pastells, aunque Furlong la atribuyó al P. Cardiel (1920). Sin embargo, décadas después se rectificó y le dio la autoría al P. Olcina (1953). Su último biógrafo, Domínguez Moltós3, no solo la publicó íntegramente, sino que le adjudicó once obras, desafortunadamente inéditas y de las que se encuentran varias cartas y relaciones sobre las misiones del Paraguay que el hermano Vicente trató de formar un tomo. Además compuso una doctrina en lengua lule, un comentario sobre la bondad de la limosna y un compendio del diccionario en lengua española. Entre ellas la más importante, cuyo manuscrito, ubicado en la Biblioteca de la RAH de Madrid, se componía de cinco tomos de los que solo se conserva el último ${ }^{54}$ en que hace una amplia exposición de toda la doctrina y moral católica. Su hermano reunió después de su muerte otros tres tomos inéditos que se hallaron un tiempo en la biblioteca de San Isidro en Madrid y luego se perdieron ${ }^{55}$. El P. Furlong llegó a publicar el único fragmento conservado en su obra sobre los vilelas de Salta (1939) y del Chaco con particular acento en los abipones (1938).

El gran misionero navarro que vivió entre los mocobíes Francisco Burgés (Pamplona, 1709-Faenza, 1777) llegó al Río de la Plata en 1729 y fue el primer fundador de una reducción mocobí dominando ampliamente su lengua, por lo que dejó un diccionario incompleto sobre ella. Durante su destierro y, como dijimos, a petición de Camaño compuso una "Relación de la fundación del pueblo de San Javier de los Mocobíes», publicada por Furlong ${ }^{56}$. Sommervogel lo confunde con su homónimo provincial de Chile y procurador del Paraguay. También de origen navarro era Román Arto (Sangüesa, 1719-Faenza, 1780), que llegó a Buenos Aires en 1749 y en el exilio escribió "Relación de los indios Tobas y Mocobíes» que brinda noticias Furlong ${ }^{57}$ pero no la publica en su libro sobre los mocobíes. También entre los mocobíes estuvo Antonio José Bustillo (Aloños, 1730-Faenza, 1796), quien arribó a Montevideo en 1755 y la expulsión lo sorprendió en la reducción

52. No obstante, el año de su muerte Prat de Saba incorpora su biografía en una de sus conocidas obras. Pero mucho más extensa fue la que escribió su hermano Vicente. El manuscrito ubicado en Sarriá se perdió en 1939, aunque fue publicado en parte por Agustín Gascó en 1886. Una excelente biografía en Domínguez Molto, Adolfo. Vicente Olcina, fabulista. Luis Olcina, misionero. Alicante: Caja Provincial de Ahorros, 1984.

53. Domínguez Molto, Adolfo. Vicente Olcina... Op. cit., pp. 143-154.

54. Explicación de las principales obligaciones de un christiano contenida en varias Doctrinas compuesta por el P. Luis Olzina de la Compañia de Jhs. Misionero del Paraguay.

55. Vicente los tituló: «Doctrinas prácticas para la instrucción del Christianismo sobre varios asuntos muy importantes. Obra póstuma del P. Luis Olzina, Presbítero, natural de Gorga, en el Arzobispado de Valencia».

56. Monografía ubicada entre los ff. 354-374 y junto al diccionario en el ARXIU (FURLONG SJ, Guillermo. Entre los en Mocobies de Santa Fe. Buenos Aires: Amorrortu e Hijos, 1938, pp. 23-35).

57. Furlong SJ, Guillermo. Entre los en Mocobies. Op. cit., pp. 377-392. 
de San Pedro de mocobíes. Compañero de Paucke entre los mocobíes, en el exilio en Brisighella profesó su cuarto voto y luego residió en Faenza. Escribió una relación sobre los mocobíes publicada por Furlong.

\section{MEMORIAS Y RECUERDOS DE LOS JESUITAS CRIOLLOS}

Tres jesuitas santafesinos se destacaron por su labor en el exilio. El moralista Tomás Uzedo (Santa Fe, 1701-Faenza, 1769) ingresó a la Compañía de Jesús a los 16 años, siendo con el tiempo profesor de humanidades y misionero entre guaraníes. Estuvo en la residencia de Jujuy y de allí el provincial Pedro Juan Andreu le ordenó ir a Tarija, pero por su enfermedad se quedó en el colegio de Salta. Para la expulsión fue arrestado en Tucumán y deportado a Italia. Según Hervás escribió tres obras ${ }^{58}$ que no mencionan Diosadado Caballero, ni Sommervogel y tampoco pudimos hallar. Oriundo de Santa Fe también fue Juan Francisco Barrenechea (Santa Fe, 1735-Rávena, 1777), que escribió una sintética relación sobre el Chaco que puso a disposición del provincial Andreu y publicó el P. Furlong en 1941.

Pero el que más se destacó fue Francisco Javier Iturri (Santa Fe, 1738-Barcelona, 1822), quien siguió trabajando en el exilio, ubicándose en Faenza y con la supresión se trasladó a Roma, donde continuó con su Historia natural, eclesiástica y civil del Virreinato del Río de la Plata, hoy perdida. Sin embargo, el P. Furlong ${ }^{59}$ nos recuerda que Enrique García Velloso le comentó haber encontrado el manuscrito en un convento de Pisa, que el historiador jesuita trató infructuosamente de

58. 1. Diccionario legal índico, o leyes de Indias, distribuidas alfabéticamente por materias. Un tomo en 4to. 2. Excelencias del glorioso Arcanjel San Rafael. Un tomo en 4to. 3. Ejercicios de San Ignacio con meditaciones, lecciones, bistoria eclesiástica, Ec. para uso de los que hacen ejercicios espirituales. Cuatro tomos en 4to. (Hervás y Panduro, Lorenzo. Biblioteca... Op. cit., p. 693).

59. Furlong SJ, Guillermo. Francisco Javier Iturri y su "Carta Crítica" (1797). Buenos Aires: Librería del Plata, 1955a, p. 73. 
hallar en Italia. Entre tanto y del P. Iturri se publicó en Madrid su Carta Crítica en 1798 (Fig. 14), escrita para refutar apreciaciones poco felices aparecidas en el libro del cosmógrafo mayor de Indias el valenciano Juan Bautista Muñoz sobre la historia del Nuevo Mundo. La obra encargada por Campomanes fue reimpresa en Buenos Aires en 1818, en México en 1820 y por el P. Furlong en 1955 como apéndice de su biografía y donde incorpora toda su obra edita e inédita. Pero también el P. Furlong en el mismo trabajo publicó una versión sobre lo acontecido con el arresto del Colegio de Asunción ${ }^{60}$ y una descripción de los pueblos de las gobernaciones del Paraguay, Río de la Plata y Tucumán, cuyo original se encuentra en una obra inédita del P. Pedro Calatayud y fue un pedido que este último le hizo para colaborar con su trabajo ${ }^{61}$. Un texto mencionado por Hervás y Panduro ${ }^{62}$, aunque desconocido su paradero, es Vantaggi delle'América sotto il dominio spagnuolo.

Especial relación tuvo el P. Iturri con el santiagueño Gaspar Juárez (Santiago del Estero, 1731-Roma, 1804), a quien le correspondería la parte histórica de la Historia natural de Iturri. Es decir que el primero escribía la parte eclesiástica y civil y Juárez la historia natural. El notable santiagueño fue de los jesuitas que dejaron una relación de la expulsión publicada parcialmente ya que el resto se encuentra perdida $^{63}$. Sus dos primeras obras impresas las publicó en Roma en colaboración con Filippo Luigi Gigli, con quien mantenía un jardín botánico en el monte Gianicolo del barrio de Trastevere hasta que fue trasladado a los jardines pontificios. La primera fue impresa en 1786, mientras que la segunda pretendía dar a luz una serie anual ilustrada con diez plantas por tomo, aparecidos en tres oportunidades en los años 1789, 1790 y $1792^{64}$ (Fig. 15). Juárez también reeditó parte de la obra de Ruiz y Pavón, agregándole sus propios aportes, anunciado en un folleto reeditado en 1795 por Antonio José Cavanillas e Hipólito Ruiz al año siguiente.

Finalmente, la correspondencia del PP. Juárez con los Funes fue publicada en dos tomos por el P. Grenón en 1920, aunque se desconoce el paradero de los manuscritos. En otro plano, el P. Juárez se interesó por el género biográfico. Recordemos que fue designado por Pío VII (1800-1823) como revisor de las causas de

60. Una se encuentra en el Archivo de los jesuitas en Alcalá de Henares y otra en el de Roma. La primera es la que publica Furlong y la segunda publicamos nosotros (PAGE, Carlos A. Relatos... Op. cit., pp. 123-153).

61. Lo mismo hizo el P. Calatayud con los PP. Guevara, Casado, Quiroga, Burgués, Arto, Aráoz, Valdés, Camaño y otros, de quienes incorpora sus aportes para una obra que firmaría en Bolonia el 8 de diciembre de 1771 y se encuentra en el AL.

62. Hervás y PANDuro, Lorenzo. Biblioteca... Op. cit., p. 614.

63. Una parte de la relación del P. Juárez la publicó el P. Grenón en 1920 y otra nosotros en 2001. Ambas en 2011, aunque solo son fragmentos de un diario más extenso y perdido.

64. Observazioni fitologiche sopra alcune piante esotiche introdotte in Roma fatte nell' Anno 1788. Roma: Nellas stamparia di Arcangelo Casalatti, 1789 con 64 pp. y con la observación del año 1789 publicado en el mismo sitio en 1790 con 70 pp. El tercer tomo con la observación de 1890 fue publicado en Roma, nella stamperia Gunchiana, a espse di Venazio Monaldini, 1792, 99 pp. 


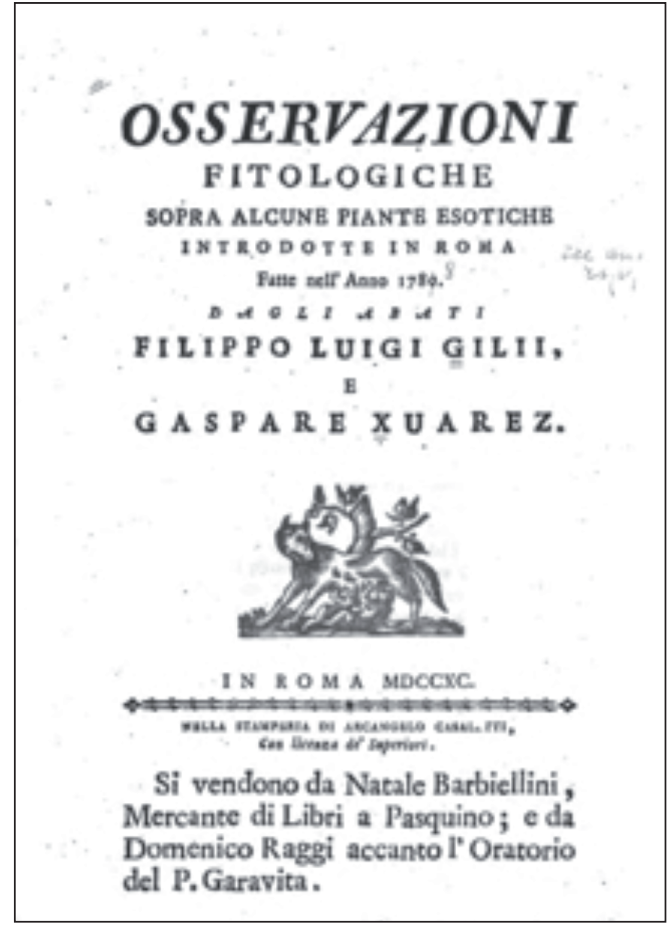

Fig. 15. Las Observazioni fitologiche que Juárez publica con Gigli entre 1789 y 1792. beatificación, para lo cual entrenó su pluma con extensas lecturas. Su primera obra en este sentido fue elogiar la vida de la madre de sus amigos de Córdoba, los Funes (1797), de quien había sido maestro espiritual y confesor. Al año siguiente emprendió una tarea con mayor vuelo al publicar una vida de san Francisco Javier, compuesta por 24 capítulos, ilustrado cada uno con una lámina, siguiendo el original del italiano Giuseppe Mase que se publicó en 1793 y que incluso le facilitó los mismos grabados. Además de la traducción en castellano, Juárez le incorporó sus propios aportes a la biografía ${ }^{65}$. Siguió en este género literario con la biografía de la Venerable Madre María Antonia de la Paz Figueroa, que permanece perdida, y luego con la del joven novicio expulso del Paraguay Clemente Baigorri, a quien el propio Luengo lo calificará como un nuevo san Luis Gonza-

ga o san Estanislao de Kostka. Hervás escribe que se tradujo al italiano y al latín. En esta lengua dice que se imprimió en Alemania, aunque ningún otro bibliógrafo trata sobre esta supuesta publicación. Lo cierto es que la misma permaneció inédita hasta hace poco tiempo ${ }^{66}$. Fue más lejos aún, pues sabemos por la correspondencia con los Funes que unos manuscritos suyos fueron colocados en un catálogo de libros escritos después del destierro, entre ellos «unas diez Vidas de Varones Ilustres de la Provincia del Paraguay». No menciona todos, solo a Francisco Ruiz [de Regis] (1745-1822), José Clemente Baigorri y el porteño José Ignacio Jaunzaras (1743-1770), agregando que aparecerían en un tomo donde también se darían noticias sobre las misiones, trabajos apostólicos y la expulsión. El texto lo

65. Recordemos que de la biografía javeriana se escribieron desde la primera del P. Manuel Teixeira de 1579, unos doscientos libros hasta la actualidad y en once idiomas. El libro del P. JuÁREZ (1798b) incluso fue reeditado en Pamplona en 2004, edición de María Gabriela Torres Olleta e impreso por la Fundación Diario de Navarra.

66. Page, Carlos A. (ed.). La vida del novicio jesuita José Clemente Baigorri escrita por el P. Gaspar Juárez. Córdoba: Báez ediciones, 2012. 
tenía escrito desde antes de la abolición (1773), pues expresa que se había leído en los refectorios de algunas casas con el título de "Cartas edificantes de la Provincia del Paraguay desde el año 1767». Finalmente, señala que las biografías estaban escritas en castellano y "las más o todas las ha traducido después en latín D. Joseph Peramas ${ }^{67}$. Sugestiva afirmación que cambiaría la autoría de la obra impresa por este último. Incluso en las cartas que envía a Gregorio Funes, le relata algunos textos sobre la historia que estaba escribiendo ${ }^{68}$ y que casualmente este último publicó con su firma un texto con el mismo tema, muchos años después. Por otro lado, varias obras registró el P. Furlong que quedaron inéditas o bien perdidas ${ }^{69}$.

También santiagueño fue el astrónomo y matemático Alonso de Frías (Santiago del Estero, 1747-Roma, 1824), a quien la expulsión lo sorprendió en el colegio de Córdoba, donde estudiaba. Residió en Faenza y con la supresión se dirigió a Milán, donde estudió y trabajó en su observatorio junto a otros jesuitas. Pasó a España con la esperanza de regresar a América, pero finalmente volvió a Italia. No se conocen impresos ni se han conservado manuscritos. Hervás y Panduro ${ }^{70}$ escribió $^{-}$ que cinco obras manuscritas y una publicada sobre astronomía fueron enviadas al observatorio de Cádiz. Mientras que el P. Storni ${ }^{71}$ menciona que varios de sus escritos se conservan en el ARSI y el P. Furlong ${ }^{72}$ escribe que otros se hallan en la Biblioteca Vittorio Emmanuele de Roma y que junto con los jesuitas Ángel de Cesaris y Francisco Reggio publicaron diversos artículos, aunque sin firmar, para la revista del observatorio de Milán publicada entre 1776 y 1803.

Ya mencionamos el texto sobre el exilio que escribió el riojano P. Castro, de donde era también Joaquín Camaño (La Rioja, Arg. 1737-Valencia, 1820), residente en Faenza y sobre todo en Imola, dedicó su tiempo al estudio etnográfico, compendios lingüísticos americanos y trabajos cartográficos con la serie de mapas publicados entre 1780 y 1789, sobre todo el compuesto para la obra del P. Jolís sobre el Gran Chaco (1789). Aunque también se conocen otros cinco mapas, como el de la gobernación de Buenos Aires compuesto para la obra perdida de Iturri-Juárez; el de la región del Orinoco inserto en el libro de Salvador Gilij (1781); un mapa de toda la América Meridional registrado por bibliógrafos de su tiempo, aunque extraviado; un mapa del Paraguay para insertar en la biografía del

67. Grenón SJ, Pedro. Los Funes y el P. Juárez. Córdoba: Tip. La Guttenberg, t. 1, 1920, pp. $181-182$

68. Nos referimos al mencionado trabajo de tres tomos de la Historia natural, civil y eclesiástica del Virreinato del Río de la Plata, compuesta con el P. Iturri, de la que tenemos noticias de su último destino en Madrid donde fue remitida para su impresión.

69. Entre ellas Disertaciones del derecho natural y de gentes, tardó para su composición más de 20 años y se ha perdido.

70. Hervás y PANDURO, Lorenzo. Biblioteca... Op. cit., p. 594.

71. Storni, H. «Frías Alfaro, Alonso de. Astrónomo». En O’Neill SI, Charles E. y Domínguez, Joaquín M. ${ }^{\text {. }}$. Diccionario Histórico de la Compañía de Jesús. Biográfico-Temático, II. Madrid: Universidad Pontificia Comillas, 2001, p. 1521.

72. Furlong SJ, Guillermo. Matemáticos... Op. cit., p. 137. 
misionero del Paraguay Luis Olcina ${ }^{73}$, que escribió su hermano Vicente, también perdida; un mapa de América extraviado al igual que el de Filipinas mencionado por Sommervogel, y otros tantos de los que solo tenemos conocimiento por sus biógrafos $^{74}$. El P. Camaño fue un extraordinario lingüista, como bien lo reconoció el propio Hervás y Panduro, además de muchos otros. Precisamente el gran filólogo recibió ayuda fundamental de Camaño en su monumental obra sobre la Idea dell'Universo, como también Gilij, quien en su conocido Saggio di storia americana (1782) introdujo observaciones de la lengua chiquita escrita por Camaño. Pero no nos han llegado sus obras inéditas excepto el texto del conocido cuaderno inédito que se encuentra en el Archivo jesuítico de Barcelona, que contiene diversas notas de jesuitas del Paraguay, como la de los PP. Canelas, Burgés, Arto, Bustillo y Camaño, que aparentemente era el material recogido por este último para componer su "Historia de América», de la que desconocemos su paradero, como el de su diccionario histórico-geográfico de Indias y otras obras menores. El P. Furlong publicó la "Noticia del Gran Chaco» en 1931 y en 1955, al igual que Maeder y otros recientemente. El P. Camaño pasó luego a España con la intención de volver a América, regresando luego a Faenza para pasar a Valencia donde fue maestro de novicios hasta su muerte. Si de mapas se trata, Sommervogel ${ }^{75}$ menciona a Juan Ignacio Deyà (Palma de Mallorca, 1730-Faenza, 1784) como autor de un mapa del Paraguay con una leyenda.

De los mismos pagos de Camaño fue Juan Francisco Ortiz de Ocampo (La Rioja, Arg., 1729-Roma, 1816). Era primo del P. Camaño, siendo misionero y profesor de Moral. Para 1798 se acogió al decreto real y viajó a Barcelona, aunque posteriormente se instaló en Nápoles en 1804. Se ocupó de escribir la historia de los guaycurúes y según el P. Hernández ${ }^{76}$ tenía impresa una novela a Nuestra Señora de Monserrat, que también cita Sommervogel ${ }^{77}$.

El teólogo Diego León de Villafañe (Tucumán, 1741-1830) fue, como dijimos, el único jesuita que como tal regresó a su Tucumán natal, no sin haber dejado en Italia una obra escrita e impresa (Fig. 16). El P. Furlong no lo valora como escritor y menos como poeta, aunque elevándolo a patriota de la Revolución, pues fue el único jesuita que participó de los sucesos relacionados con la Revolución de Mayo, incluso como actor de aquellos acontecimientos. Hace poco tiempo hallamos en la Biblioteca Nacional Braidense de Milán dos obras publicadas en Roma

73. El P. Furlong expresa que el P. Luis Olcina es el autor de una obra sobre «Recuerdos del Gran Chaco» que Godofredo Kaspar atribuyó erróneamente al P. Cardiel y publicó en la Revista de la Academia del Plata (a. 9, t. XVIII, enero/junio, 1920).

74. Furlong SJ, Guillermo. Joaquín Camaño S.J. y su "Noticia del Gran Chaco» (1778). Buenos Aires: Librería del Plata, 1955b.

75. Sommervogel SJ, Carlos. Bibliothèque de la Compagnie de Jésus. Nouvelle Édition. Tome III, Bruselas: Oscar Schepens y París: Alphonse Picard, 1892, p. 28.

76. Hernández SJ, Pablo. Colección de libros y documentos... Op. cit., p. 518.

77. Sommervogel SJ, Carlos. Bibliothèque... Op. cit., VI, p. 1859. 
(1792a y 1792b). Escribe contra un texto del jesuita Giovanni Vincenzo Bolgeni sobre la caridad cristiana. El P. Furlong no conoció las obras sino que siguió los buenos comentarios que de las mismas hizo el P. Luengo ${ }^{78}$, aunque aparentemente el vallisoletano tampoco las leyó, como se mencionó en otra oportunidad ${ }^{79}$. Ambos libros fueron registrados por Uriar$\mathrm{te}^{80}$. Lo valioso de sus escritos son las numerosas cartas que escribe y que por suerte la mayoría fueron publicadas por Furlong ${ }^{81}$ y que incluyen dos memoriales al gobernador intendente de Cuyo, cartas a Funes donde deja entrever varias obras que tenía escritas que no se publicaron y que hoy se encuentran extraviadas, e incluso cartas a Gaspar Juárez y otros jesuitas exiliados. El Archivo General de la Nación (Argentina) conserva un texto inédito sobre el uso de la Santa Biblia en lengua vulgar de $1802^{82}$.

Mencionamos antes una serie de jesuitas que enviaron sus valiosos escritos al P. Camaño, entre ellos el misionero criollo entre mocobíes Manuel Canelas (Córdoba, Arg., 1718-Faenza, 1773). Ingresó a la Compañía de Jesús en 1739 y a pedido de Camaño escribió "Origen de la nación Mocobí y relato de sus usos y costumbress ${ }^{83}$.

78. AL, t. 26, año 1792 , pp. 543-546 y año 1793 , pp. 287-288.

79. Lovay, Silvana M. y PAGe, Carlos A. «El regreso del P. Diego León de Villafañe, último jesuita de la antigua Provincia del Paraguay». IHS. Antiguos jesuitas en Iberoamérica, Córdoba, 2013, I, 2, pp. 155-169.

80. URIARTE, J. E. de. Catálogo razonado de obras anónimas y seudónimas de autores de la C. de J. pertenecientes a la antigua asistencia española. I. Madrid: Establecimiento tipográfico "Sucesores de Rivadeneyra", 1904, pp. 272-273 y 502.

81. Furlong SJ, Guillermo. Historia del Colegio de la Inmaculada de la ciudad de Santa Fe y sus irradiaciones culturales, espirituales y sociales, 1610-1962, t. 1. Buenos Aires: Sociedad exalumnos, $1962 \mathrm{~b}$

82. AGN, BN, ms. 4308.

83. Monografía ubicada entre los ff. 177-347 en el ARXIU (publicada en FurLONG SJ, Guillermo. Entre los en Mocobies... Op. cit., pp. 78-118). También ver sobre el tema en: SALINAS, María Laura y 
Se destacan también el criollo Roque Gorostiza (Tarija, 1726-Roma, 1808), quien ingresó a la Compañía de Jesús en 1745 y escribió sobre tres entradas a los vilelas que hizo una con el P. Jolís y otra solo ${ }^{84}$. Además de lingüistas como Francisco Legal (Asunción, 1724-Faenza, 1779), quien escribió, según recuerda Sommervoge ${ }^{85}$, una gramática en guaraní inserta en la obra de Gilij publicada en Roma en 1782.

Para concluir mencionaremos al mendocino Juan Ramón Videla (Mendoza, 1749-Roma, 1811), quien ingresó a la Compañía de Jesús en 1765 y estudió en Córdoba. Para la expulsión se estableció en Faenza, regresando a España en 1798 para luego volver a Italia. Videla contaba por entonces con 85 años, cuando escribió una carta desde la restablecida Nápoles en 1805, relatando los acontecimientos surgidos de aquel momento, incluso cuenta que el provincial San José Pignatelli le encargó que escribiera una relación para ser impresa. La publica íntegramente Furlong ${ }^{86}$. Pero el anciano regresó a Roma y estando en el colegio del Gesú fue asesinado por el joven enfermero Luis Piroli en un extraño incidente, que también llevó la vida del coadjutor español radicado en Chile Juan Antonio Trebuesto Fueros, acontecimiento redactado por Hanisch ${ }^{87}$ siguiendo a Luengo.

\subsection{Autores con obras perdidas e inéditas}

Varias obras ya hemos mencionado que quedaron inéditas como, entre otras, las de los jesuitas Peramás, Sans y Borrego. O bien se hallan perdidas como las de Muriel, Pellejá, Jolís, Fernández, Olcina, Iturri y Juárez; e incluso tienen trabajos tanto inéditos y perdidos como Sánchez Labrador. Un caso especial es, dentro de la temática historográfica, José Guevara (Recas, 1719-Spello, 1806), quien llegó a Buenos Aires en 1734 y para la expulsión se hallaba en Córdoba, donde se lo despojó de sus escritos con la idea de encontrar entre ellos pruebas comprometedoras contra los jesuitas. Residió en Faenza, fue rector del colegio de Brisighella y canónigo de la catedral de Spello de la diócesis de Foligno. Hervás señala cuatro obras impresas entre 1775 y 1790, aunque la última de ellas, si bien fue mencionada como impresa por otros bibliógrafos, Lamas la considera inédita y no solo

\footnotetext{
Valenzuela, Fátima V. "Los mocobíes del Chaco según la mirada del P. Manuel Canelas SJ». IHS. Antiguos jesuitas en Iberoamérica, 2015, III, 2, pp. 169-190.

84. Se titula "Breve noticia de las tres entradas que hizo el Padre Roque Gorostiza, dos de ellas solo y la tercera con el Padre Joseph Jolís» y la reproduce íntegramente el P. Furlong en 1939, tomándola del ARXIU.

85. Sommervogel SJ, Carlos. Bibliothèque... Op. cit., IV, 1658.

86. Furlong SJ, Guillermo. Francisco Javier Iturri y su "Carta Crítica" (1797). Buenos Aires: Librería del Plata, 1955a, pp. 24-26.

87. HanisCH SJ, Walter. Itinerario y pensamiento de los jesuitas expulsos de Chile (1767-1815). Santiago de Chile: Ed. Andrés Bello, 1971, p. 160.
} 
no la hemos hallado, sino que desconocemos incluso su manuscrito original ${ }^{88}$. Su trabajo más conocido es sobre la historia del Paraguay, impreso parcialmente en 1836 sobre un original hoy perdido y reeditado tres veces $(1836,1882,1908)$. La obra manuscrita completa en dos tomos, hoy desaparecida, fue escrita en América y el P. Guevara la obsequió a los dominicos de Tucumán. Tampoco sabemos del paradero de dos obras que dejó en el colegio de Córdoba referidas al obispo Cárdenas y que mencionó el propio Hervás ${ }^{89}$.

Entre estos desafortunados autores también se encuentra Manuel Arnal (Teruel, 1710-Ferrara, 1787), que había llegado a Buenos Aires en 1734, pasando a las misiones guaraníticas, aunque la expulsión lo sorprendió en Buenos Aires. Sabemos por Uriarte y Lecinas que tenía un trabajo refutando al exjesuita Ibáñez de Echávarri que estaba en poder del P. Muriel ${ }^{90}$. También Hervás menciona tres obras inéditas de Arnal, aunque desconocemos el paradero ${ }^{91}$. Se suma Pedro Campos (Ciudad Rodrigo, 1743-Faenza, 1799), que llegó a Buenos Aires en 1764 para continuar sus estudios en Córdoba donde fue arrestado y trasladado a Faenza y luego Génova. De allí envió a Madrid en 1789 tres tomos manuscritos ${ }^{92}$ que fueron censurados por Floridablanca por recomendación de Azara, quien lo consideraba de los jesuitas más subversivos ${ }^{93}$.

Otro escritor que no dejó obra conocida en el exilio es Juan de Escandón (Celucos, 1696-Faenza, 1772), curiosamente no mencionado por Hervás y advertido

88. 1.-Dissertatio Antiblasiana, seu Blasius admonitor in Blasium Commonitorem. Venecia: Typis Bettinelli, 1775. Dissertatio bistorico-dogmatica de Sacrarum imaginum cultu religioso quator epochis complectens dogma, et disciplinam Ecclesiae super sanctas imagines. Foligno: Typis Jesualdi Fofi, 1789. 2.-Dissertazione sopra gli oracoli nella quale si fa manifesto contra Fontanelle che il demonio ebbe parte negli oracoli degli antichi. Foligno: Per Gesualdo Fofi, 1790. 3.-Risposta all'anonimo della lettera sopra la vicinanza del iudizio universale. Foligno: Per Giovanni Tomassini, 1790 y 4.-De abusu superstitioso rerum sacrarum Degli oracoli (HERVÁs y PANDURO, Lorenzo. Biblioteca... Op. cit., p. 257).

89. Vida del Ilustrisimo señor Don Bernardino Cárdenas, obispo del Paraguay y Disertación sobre la fe y crédito que se deben dar a las imposturas del señor Obispo D. Bernardino de Cárdenas, confirmándolo todo con Reales Cédulas, determinaciones de la Real Audiencia de Lima, del juez conservador, deposición de testigos de vista y oído, y con los escritos originales del mismo obispo (HERVÁs y PANDuro, Lorenzo. Biblioteca... Op. cit., pp. 258-259 y SOMmervoGEL SJ, Carlos. Bibliothèque de la Compagnie de Jésus. Nouvelle Édition. Tome III. Bruselas: Oscar Schepens y París: Alphonse Picard, 1892, p. 1923).

90. Del fabuloso reino jesuítico en el Paraguai, contenido en los cuatro libros de Ibáñez y en el librillo de la "República del Paraguay", que se presentó a Benedicto, papa, XIV.

91. 1.-Synopsis operis anonymi (italice editi in IV voluminibus) de jure libero ecclesiae ad possidenda bona temporalia, un tomo en folio. 2.-Synopsis Ante-Febronii italica editi Caesenae, typis Gregorii Biasini, et auctore Francisco Antonio Zaccaria Soc. J. In IV voluminibus, in folio y 3.-Vitae et praedictionum beati Joachimi Abbatis super futuro clericorum regularium ordine. Liber singularis, in 4 to.

92. Auctoritas, et aequitas summa constitutionis “Unigenitus", \&., adversus veteres, et novissimos calumniatores.

93. Hervás y Panduro, Lorenzo. Biblioteca... Op. cit., p. 593. 


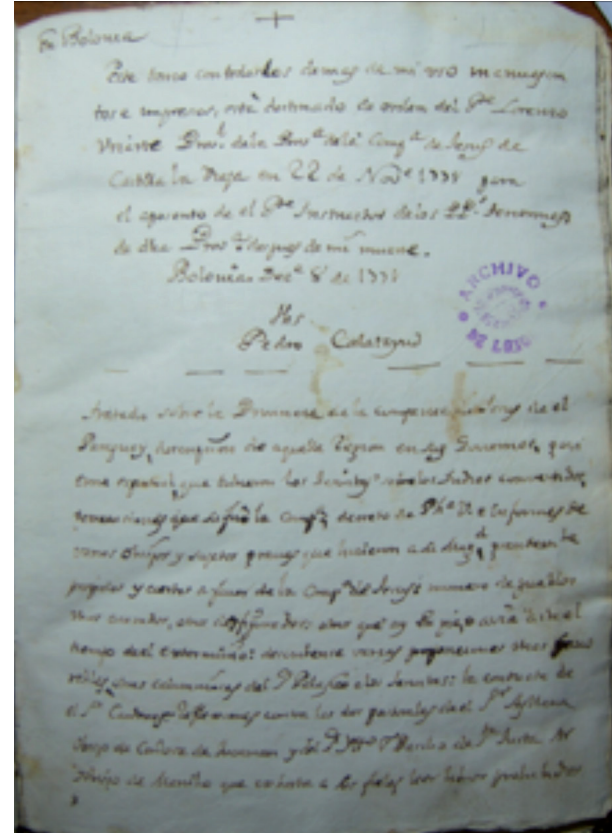

Fig. 17. Inédito tratado de la provincia del Paraguay del P. Calatayud (1771).

por Astorgano Abajo ${ }^{94}$. Llegó a Buenos Ares en 1734 y alcanzó el cargo de procurador en Europa (1757-1764). Con la expulsión se desempeñaba como maestro de novicios, experimentado y muy querido jesuita que había dejado en América profundos escritos, pero que en el exilio, seguramente por su avanzada edad, no llegó a publicar nada. Según Peramás y sigue Furlong 95 dejó inédita una traducción al castellano de una obra pequeña que era la respuesta del cardenal Belarmino a dos libelos y otra del mismo cardenal sobre un entredicho de Paulo V con fray Paulo Servita, que no hemos podido encontrar. Tampoco lo menciona Hervás, pero también fue estudiado por Astorgano Abajo, el navarro Francisco Javier Mariátegui (Sangüesa, Navarra, 1741-¿1814?), joven que estuvo en el Paraguay solo tres años. Sabemos que remitió a Godoy una novela histórico-pedagógica antifilosófica, compuesta en 1785 de tres tomos, que no se publicó debido a la censura de Grimaldi. También Campomanes lo censura en una obra que implora poder regresar a su patria. Pero fueron textos que el mismo Mariátegui confiesa haber escrito para recibir la doble pensión que se comenzó a otorgar en $1785^{96}$.

Se suma el esloveno Ignacio Cierhaimb (Hofenbach, 1703-Alba Real, 1773), misionero entre guaraníes que llegó en 1734 y fue arrestado en Mártires y del que Sommervogel ${ }^{97}$ cita tres obras escritas en el Paraguay.

No son pocas las obras que han permanecido inéditas o se han extraviado. El P. Pedro Antonio de Calatayud (Tafalla, 1689-Bolonia, 1773) fue destinado al Paraguay en 1716, pero no alcanzó a viajar, permaneciendo en España hasta la expulsión, momento en que se encontraba en Valladolid. Se propuso escribir desde Bolonia un tratado de 19 capítulos sobre el Paraguay y para ello pidió la

94. Hervás y PANDURo, Lorenzo. Biblioteca... Op. cit., p. 60.

95. Furlong SJ, Guillermo. Juan de Escandón SJ y su carta a Burriel (1760). Buenos Aires: Ediciones Theoria, 1965, p. 78.

96. Astorgano ABAjo, Antonio. «Un jesuita expulso sangüesino rebelde: Francisco Javier Mariátegui. El ex jesuita oprimido". Revista Príncipe de Viana, 2011, LXXII (252), pp. 196-200.

97. Sommervogel SJ, Carlos. Bibliothèque... Op. cit., I, p. 1189. 
ayuda de varios jesuitas que estuvieron en las misiones, conservándose el índice del trabajo y varias colaboraciones enviadas por distintos jesuitas americanos. Casi todo inédito se encuentra en el Archivo de Loyola ${ }^{98}$ (Fig. 17).

\section{PARA IR CERRANDO CON ALGUNA REFLEXIÓN}

Como hemos mencionado y queremos reafirmar, parecía que los jesuitas expulsos estaban escribiendo no solo para lectores de su tiempo, sino dejando asentada su labor en América que sabían que sería borrada de la historia. Como efectivamente pretendían los borbones, destruyendo el «mito» de Muratori. Parafraseando a Yerushalmi, existía en el ambiente un fuerte terror al olvido, aún más poderoso que el temor de tener que recordar demasiado. La memoria no se contrapone al olvido y rememorar el pasado era una necesidad a fin de afirmar la identidad propia y negar otra memoria. Recuperar la identidad era el objetivo para sentirse libres. Pues esa identidad no provenía de Roma, como centro eclesiástico, ni de España, metrópoli de América, sino de los inolvidables paisajes y personas que no pudieron volver a ver.

La reincorporación de la Compañía de Jesús al mundo católico no fue suficiente reparo ante el daño producido. Costó varias décadas para recuperar el prestigio de otrora. Y se comenzó reivindicando los escritos de los exiliados que fueron lentamente publicados y abriendo las fronteras a una comprometida identificación con la historia. Los historiadores jesuitas supieron abrir el camino a generaciones de laicos que siguieron con entusiasmo recorriendo aquellas huellas. El conocimiento de su pasado les devolvió presencia identitaria y luego se revalorizó su labor temporal a través de sus monumentos. Un poco más de un siglo llevó esta ininterrumpida labor de quitar los prejuicios e instalar en la sociedad una renovada reputación hasta alcanzar algo que nunca habían pretendido: el actual pontificado.

Un grupo de los jesuitas en su exilio italiano se dedicaron a redactar obras enmarcadas dentro de una literatura edificante y apologética, jurídica y filosófica. Otros contribuyeron a refutar a los detractores de la conquista y a escribir trabajos científicos notables que fueron en su tiempo elogiados. En este aspecto siguieron el gusto y el pensamiento de la Ilustración por la ciencia. Siempre bajo la mirada inquisitorial que observaba con malos ojos la producción jesuita y, sobre todo, los temas devocionales.

Los jesuitas del Paraguay, al igual que la mayoría de los exiliados, comenzaron a publicar después de la supresión, que fue un momento mucho más duro que la misma expulsión. En este sentido los extranjeros tuvieron más fortuna, ya que el primero que logró llevar un texto a imprenta, aunque en extracto, fue el

98. AL, $17 / 3$. 
P. Falkner (1774). Tuvo relativo éxito pues rápidamente su trabajo se imprimió en otros idiomas, aunque en castellano en 1835. Pero no es de sorprender, pues la mayoría de los libros alcanzaron la lengua hispana en el siglo XIX y aun en el XX.

Nos interesa esa particular preocupación historiográfica por la cultura aborigen como reconocimiento de la cultura hispanoamericana de raíz indígena. Pues trataban de demostrar que los americanos no solo tienen cultura, sino también historia, como el conocido postulado de Giambatista Vico. Y dentro de esa valoración cultural se reivindica a rajatabla el saber autóctono.

Los jesuitas no dejaron que se apoderara el olvido de la memoria colectiva construida, que incluía la experiencia de la alteridad americana. No estaban dispuestos a someterse al "pasado ausente de los vencidos" e iban a defender esa América diferente que habían construido con gran sacrificio. Abrieron un debate sobre el continente como no había existido desde el "descubrimiento» y no solo valorizando la otredad, sino la propia identidad ibérica, amenazada ante las críticas extranjeras que en ciertos aspectos dejaban al descubierto las debilidades de la conquista.

De tal manera que, de las obras aparecidas durante el exilio, prevalecen trabajos con temas diversos con una marcada tendencia ecléctica e incluso enciclopedista como por entonces estaba en boga. Aunque también influyeron las frecuentes corrientes clasicistas ilustradas, encuadradas en el latinismo, porque la lengua del Lacio les facilitaba la comunicación con sus pares los italianos. Incluso usando seudónimos italianizados como Muriel, Serrano y Cardiel.

Había, como dice Astorgano Abajo, una necesidad de demostrar que, a pesar de ser perseguida y suprimida, la Compañía de Jesús continuaba trabajando y esa posibilidad se manifestó -siguiendo a Luengo- luego de desatada la competencia entre literatos italianos como Tireboschi y Bettinelli y los hispanos Serrano, Andrés y Llampillas, pues se inició una intensa actividad intelectual en provecho de la Compañía de Jesús y el objetivo máximo de verla restaurada.

\section{ARCHIVOS}

AGN-BN: Archivo General de la Nación Argentina, fondo Biblioteca Nacional (Buenos Aires).

AHPT: Archivo de la Provincia jesuítica de Toledo (Alcalá de Henares).

AL: Archivo de Loyola (Azpeitia).

ARSI: Archivo Romano de la Compañía de Jesús (Roma).

ARXIU: Archivo Histórico de la Compañía de Jesús de Cataluña (Barcelona).

RAH: Real Academia de la Historia (Madrid). 


\section{Bibliografía}

Astorgano Abajo, Antonio. "La Biblioteca jesuítico-española de Hervás y Panduro y su liderazgo sobre el resto de los ex jesuitas». Hispania Sacra, 2004, LVI, 113, pp. 170-268.

Astorgano Abajo, Antonio. "Un jesuita expulso sangüesino rebelde: Francisco Javier Mariátegui. El ex jesuita oprimidon. Revista Príncipe de Viana. 2011, 252, pp. 181-252.

AZNAR, Juan Francisco. Instruzione utile alla Gioventu per degolare se stessa nella vita civile, é morale cristiana. Data alla Luce del S. Abbate Francisco Aznar. Ferrara: per Gli Eredi di Giuseppe Rinaldi, 1786.

AZNAR, Juan Francisco. Lettera pastorale dell' illmo, e revmo. mons. Dn. Francisco Valerio e Lossa, arcivescovo de Toledo, nella quale manifesta a tutti suoi sudditi e motivi, che vi sono di temere, che l'ignoranza delle verità cristiane sia caggione di quello si crede etc. Tradotta dall' idioma espagnuolo del sacerdote Dn. Francisco Aznar. Ferrara: Per Francesco Pomatelli, 1791.

BATLLORI SI, Miguel. La cultura hispano-italiana de los jesuitas expulsos, españoles, hispanoamericanos, filipinos, 1767-1814. Madrid: Ed. Gredos, 1966.

BINAYAN CARMONA, Narciso. "Los primeros croatas en la Argentina». Studia Croatica, Buenos Aires, 1971, XII, 42-43, pp. 122-124.

CARDiel, José. Compendio de la Historia del Paraguay. Estudio preliminar de José María Mariluz Urquijo. Buenos Aires: Fundación para la Educación, la Ciencia y la Cultura, 1984.

Cardiel, José. Breve Relación de las misiones del Paraguay. Prólogo de Ernesto J. A. Maeder. Buenos Aires: Ediciones Theoría, 1994.

DeCKMann Fleck, Eliane Cristina. As artes de curar em um manuscrito jesuítico inédito do Setecentos. São Leopoldo: Editora Unisinos, 2015.

DOBRIZHOFFER, Abbé Martín. Geschichte der Abiponer, einer berittenen und kriegerischen Nation in Paraquay... 3 vols. Wien: bei Joseph Edlen von Kurzbek, 1783-1784.

Dobrizhoffer, Martín. Historia de Abiponibus Equestri, Bellicosaque Paraquariae natione Locupletata Copiosis Barbararum Gentium, Urbium, Fluminum, Ferarum, Amphibiorum, Insectorum, Serpentium Praecipuorum, Piscium, Avium, Arborum, Plantarum, Aliarumque Eiusdem Provinciae, Proprietatum Observationibus. Veinae: Typis Josephi Nob. De Kurzbek, 1784.

Dobrizhoffer, Martín. An account of the Abipones, an equestrian people of Paraguay. [bigote] From the latin of Martin Dobrizhoffer, eighteen years a missionary in that country. [bigote] In three volumes III Vols. London: John Murray, Albemarle street, 1822.

Dobrizhoffer, Martín. Historia de los Abipones. Traducción de Edmundo Wernicke. Advertencia editorial del Profesor Ernesto J. A. Maeder. Noticia biográfica y bibliográfica del Padre Martín Dobrizhoffer, por el Académico R. P. Guillermo Furlong S. J. Resistencia. Chaco: Universidad Nacional del Nordeste, Facultad de Humanidades, Departamento de Historia, 3 vols., 1967-1969.

Domínguez Molto, Adolfo. Vicente Olcina, fabulista. Luis Olcina, misionero. Alicante: Caja Provincial de Ahorros, 1984.

FalKner, Thomas. A description of Patagonia and the Adjoining Parts of South America: containing an account of the Soil, Produce, Animals, Vales, Muntains, Rivers, Lakes, \& of those countries. The religion, Gobernment, Policy Customs, Drefs, Arms, and Language of the Indian Inhabitants; and some Particulars relating to Falkland's Island. Hereford: Printed by Puch and sold by T. Lewis, Russel-Street, Covent-Garden, London, 1774. 
FALKNER, Thomas. Of the Patagonians. Formed from the relation of Father Falkener a Jefuit who had refided among them thirty eight Years. And from the different Voyagers who had met with this tall race. Printed by the friendship of George Allan Esq. at his private press at Darlington, 1788.

FERnÁNDEZ ARrillaga, Inmaculada. El destierro de los jesuitas castellanos (1767-1815). Salamanca: Junta de Castilla y León, 2004.

FuRLONG SJ, Guillermo. «Lorenzo Hervás y las lenguas indígenas americanas». Estudios, Buenos Aires, 1927, 32, pp. 210-214, 291-294.

FurLONG, SJ. Guillermo. La personalidad y la obra de Tomás Falkner. Buenos Aires: Talleres de Jacobo Peuser, 1929.

FurLONG SJ, Guillermo. "Datos sobre los indios chunupíes y omoampas, reunidos por el Padre A. Maxí en 1763". Revista Solar, Buenos Aires, 1931, pp. 299-318.

FurLong SJ, Guillermo. Entre los en Mocobies de Santa Fe. Buenos Aires: Amorrortu e Hijos, 1938.

FuRLONG SJ, Guillermo. Entre los Vilelas de Salta. Buenos Aires: Academia Literaria del Plata, 1939.

FurLong SJ, Guillermo. Entre los lules de Tucumán. Buenos Aires: Talleres gráficos San Pablo, 1941.

FURLONG SJ, Guillermo. Matemáticos argentinos durante la dominación hispánica. Buenos Aires: Editorial Huarpes, 1945a.

FurLong SJ, Guillermo. «Vicente Sans y José Sans». Estudios, Buenos Aires, 1945b, 397, pp. 250-264

FURLONG SJ, Guillermo. Naturalistas argentinos durante la dominación hispánica. Buenos Aires: Ed. Huarpes, 1948.

FuRLONG SJ, Guillermo. Nacimiento y desarrollo de la filosofía en el Río de la Plata. 15361810. Buenos Aires: Ed. Guillermo Kraft Limitada, 1952.

FurLong SJ, Guillermo. José Cardiel y su Carta-Relación (1747). Buenos Aires: Librería del Plata, 1953.

Furlong SJ, Guillermo. Tomás Falkner y su «Acerca de los Patagones» (1788). Buenos Aires: Librería del Plata, 1954a.

FurLONG SJ, Guillermo. Matemáticos argentinos durante la dominación hispánica. Buenos Aires: Editorial Huarpes, 1954b.

Furlong SJ, Guillermo. Francisco Javier Iturri y su "Carta Crítica" (1797). Buenos Aires: Librería del Plata, 1955a.

FurLong SJ, Guillermo. Joaquín Camaño S.J. y su "Noticia del Gran Chaco" (1778). Buenos Aires: Librería del Plata, 1955b.

Furlong SJ. Guillermo. Domingo Muriel y su relación con las misiones (1766). Buenos Aires: Librería del Plata, 1955c.

Furlong SJ, Guillermo. Diego León Villafañe y su "Batalla de Tucumán» (1812). Buenos Aires: Ediciones Theoría, 1962a.

Furlong SJ, Guillermo. Historia del Colegio de la Inmaculada de la ciudad de Santa Fe y sus irradiaciones culturales, espirituales y sociales, 1610-1962, t. 1. Buenos Aires: Sociedad exalumnos, 1962.

FuRlong SJ, Guillermo. Francisco Miranda y su sinopsis (1772). Buenos Aires: Ed. Theoria, 1963.

FuRLONG SJ, Guillermo. Juan de Escandón SJ y su carta a Burriel (1760). Buenos Aires: Ediciones Theoria, 1965. 
LA LITERATURA DE LOS JESUITAS EXPULSOS DE LA PROVINCIA DEL PARAGUAY. MEMORIAS DE UNA INTENSA LABOR

GIL, Manuel Gervasio. Theoria Boscovichiana vindicata et defensa ab impugnationibus, quibus impetitur in dissertatione quadam. De singulari systemate, aut hypothesi. $P$. Boschovich circa legem continuitatis, et contractum corporum, ab aliorum quoque difficultatibus in eamdem oppositis hac occasione expeditur. Auctore sacerdote hispano. Fulginiae: Apud Joannem Tomassini, Impress. Espiscop, 1791.

GIL, Manuel Gervasio. Dissertatio de viribus repulsivis in natura existentibus. Propugnabitur cum subjectis Thesibus a binis, quos sors tulerit, et tribus lectissimis et studiosissimis adolescentibus, Carolo Anguissola, Josepho Belloti, Dominico Lusardi, in D. Petri Placentiae, anno Domini MDCCXCVIII, mense Junio. Plasentiae: Excudebat Josephus Tedeschi, 1798.

GIL, Manuel Gervasio. Disquisitio in causam physicam recentium chemicorum pro elasticitate aeris atmosphaerici, et aliorum fluidorum elasticorum, quae Gas nuncupantur: Cum appendice de causa fluiditatis. Placentiae: Excudebat Josephus Tedeschi, 1799.

Grenón, Pedro SJ. Los Funes y el P. Juárez. Córdoba: Tip. La Guttenberg, t. 1, 1920.

GuAsti, Niccoló. "Rasgos del exilio italiano de los jesuitas españoles». Hispania Sacra, Madrid, 2009, LXI, 123, pp. 257-278.

HANISCH SJ, Walter. Itinerario y pensamiento de los jesuitas expulsos de Chile (1767-1815). Santiago de Chile: Ed. Andrés Bello, 1971.

HERNÁNDEZ SJ, Pablo. Colección de libros y documentos referentes á la historia de América. Tomo VII. El extrañamiento de los jesuitas del Río de la Plata y de las misiones del Paraguay. Madrid: Librería General de Victoriano Suárez, 1908.

HeRvás y PANDURO, Lorenzo. Biblioteca Jesuítico-Española (1759-1799). Estudio introductorio, edición crítica y notas Antonio Astorgano Abajo. Madrid: Libris, 2007.

ITURRI, Francisco. Carta crítica sobre la Historia de América del señor D. Juan Bautista Muñoz escrita de Roma. Madrid, 1798.

Jolis, Giuseppe. Saggio sulla storia naturale della provincia del Gran Chaco e sulle pratiche, e su costumi dei Popoli che ne l'abitano, t. 1. Faenza: per Lodovico Genestri, 1789.

Jú́REZ, Gaspar. Observazioni fitologiche sopra alcune piante esotiche introdotte in Roma fatte nell'Anno 1788. Roma: Nellas stamparia di Arcangelo Casalatti, 1789.

Jú́REZ, Gaspar. Conspectus novae editionis florae peruvianae et Chilensis, quan Romae parat Gaspar Xuarez. Romae, 1795.

JuÁreZ, Gaspar. Elogia de la Señora María Josepha Bustos. Roma, 1797 (reeditada por Luis Alberto Altamira en 1949).

JuÁREZ, Gaspar. Decade di Alberi curiosi ed eleganti piante delle Indie orientali e dell'America. Roma: Salomoni, 1798a.

Jú́reZ, Gaspar. Vida iconologica del Apostol de las Indias San Francisco Xavier de la Compañia de Jesus por Gaspar Xuárez. Roma: en la imprenta de Miguel Puccineli, 1798b.

LAGUA, Nicolás. Regole di buona pronunzia e ortografia latina ed italiana delle declinazioni de' nomi greco-latini con una breve istruzione da scrivere lettere, per uso dei signori marchesi Girolamo e Pompeo Muti Papazzurri, patrizi romani, proposte dal loro maestro l'abate D. Nicolò Lagua. Roma: Per Luigi Perego Salvioni, 1788.

LAGuA, Nicolás. Lettera di San Ignacio di Loyola a Claudio imperatore dell'Etiopia, e re degli Abissini, nella quale si defende il Primato, e la Suprema Autorità del Romano Pontefice, e l'unità della Chiesa, tradotta dal latino, ed illustrata con note dall' abate Niccolò de Lagua. Con una notizia preliminare in torno all'Etiopia, ed ad alcune particolarità della stessa lettera. Roma: Nella Stamperia Pagliarini, 1790. 
LAGUA, Nicolás. Istruzioni morali per uso principalmente de "Cavalieri Cristiani proposte dall' Ab. D. Niccolò de Lagua. Roma: dalle stampe del Vescovi a SS. Apostol, 1798.

LATASSA y OrTín, Félix de. Biblioteca nueva de los escritores aragoneses que florecieron desde el año de 1795 hasta el de 1802. Pamplona: Oficina de Joaquín de Domingo, t. VI, 1802.

LovaY, Silvana M. y PAGe, Carlos A. «El regreso del P. Diego León de Villafañe, último jesuita de la antigua Provincia del Paraguay». IHS. Antiguos jesuitas en Iberoamérica, Córdoba, 2013, I, 2, pp. 155-169.

MaEder, Ernesto; Salinas, M. Laura; Folkenand, Julio y Braunstein, José (comps.). Entre los Jesuitas del Gran Chaco. Compilación de Joaquín Camaño S.J. y otras fuentes documentales del siglo XVIII. Buenos Aires: Academia Nacional de Ciencias, 2016.

MENÉNDEZ y PELAYO, Marcelino. Historia de las ideas estéticas en España. Madrid: CSIC, vols. $1,1993$.

MiLlás SI, Joaquín. Saggio sopra i tre generi di poesia in cui Virgilio si acquistò il titolo di principe: con un confronto dei greci e degl'italiani poeti che abbraccerà le relazioni della poesia con le belle arti: che darà al pubblico il signor Lorenzo Tamarozzi sotto la direzione del sig. ab. Giovacchino Millas. Mantova: nella stamperia di Giuseppe Braglia, 1785.

Millás SI, Joaquín. Dell'unico principio svegliatore della ragione, del gusto e della virtú nell'edacazion letteraria, 3 vols. Mantova: nella stamperia di Giuseppe Braglia, 1786-1788.

MiLlás SI, Joaquín. Sopra el disegno e lo stile del sermon poetico italiano. Dissertazione dell' Abate Giovachino Millas di Saragozza al Cav. Clementino Vannetti in ocasione d'un suo sermone. Verona, 1790.

Millás SI, Joaquín. Propositiones praecipuae Logices, argumenta complectens, desumptae ex tractationibus metaphysicis, quas in regia Placentina Academia anno 1797 explicavit Sacerdos Hispanus Joachim Millas, Disciplinarum Metaphisicarum Professor. Placentiae: Joseph Tedeschi, 1797a.

Millás SI, Joaquín. Psychologiae Institutiones. Piacenza, 1797b.

MiLlás SI, Joaquín. Introductio ad metaphysics disciplinas, prolegomenon dúplex de contemplatione et historia philosophia complectens, et logices totius analysim asque accomodationem precipuis rationis et auctoritatis in veritatis investigatione..., 1798.

MiRANDA SJ, Francisco Javier. «Los novicios de Córdoba del Tucumán y otros novicios Americanos. Relato de sus pruebas y constancia en seguir la Compañía de Jesús en la expulsión de Carlos III». Revista Eclesiástica del Arzobispado de Buenos Aires, 1906, 6, pp. 199-209, 285-297, 367-380.

MiRANDa SJ, Francisco Javier. Vida del Venerable sacerdote Don Domingo Muriel, religioso un tiempo de la abolida Compañia de Jesús y último provincial de su Provincia del Paraguay, escrita por un discípulo suyo sacerdote de la misma Compañia. Córdoba: Universidad Nacional de Córdoba, 1916.

MiRANDa SJ, Francisco Javier. El perro de Diógenes. Edición, actualización y notas Daniel Teobaldi, Alfredo Fraschini, Juan Kalinowski, Fabiana Demaría de Lissandrello y Lidia del Valle Moreira. Córdoba: Universidad Nacional de Villa María, 2010.

MiRANDA SJ, Francisco Xavier. El fiscal fiscalizado. Una apología de los jesuitas contra Campomanes. Estudio introductorio, transcripción y notas de Enrique Giménez López. Alicante: Publicaciones de la Universidad de Alicante, 2013. 
LA LITERATURA DE LOS JESUITAS EXPULSOS DE LA PROVINCIA DEL PARAGUAY. MEMORIAS DE UNA INTENSA LABOR

MuRIEL SJ, Domingo. Lettre a l'auteur de l'article Jésuite dans le Dictionnaire encyclopédique: ou Compte rendu de cet article a son auteur. París, 1766.

MuRIEL SJ, Domingo (traductor). Práctica de los Exercicios de S. Ignacio por el P. Ignacio Diertins de la Compañía de Jesus. Danse repartidos en meditaciones para todos los dias del año. Faenza: Antonio Archi, 1772.

MuRIEL SJ, Domingo. Fasti novi orbis et ordinationum apostolicarum ad Indias pertinentium breviarium cum anotationibus. Opera D. Cyriaci Morelli, presbiteri, olim in universitate neo-cordubensi in tucumania professoris. Venecia: Prostat Apud Antonium Zatta, 1776.

Muriel SJ, Domingo (traductor). Principios de la Vida Espiritual sacados del Libro de la Imitación de Jesu Christo por el P. Joseph Surin. Traducción del original francés. Cesena: Imprenta de Gregorio Biasini, 1778.

MuRIEL SJ, Domingo. Rudimenta Juris Naturae et Gentium Libri Duo auctore D. Cyriaco Morelli Presbytero olim in Universitate Neo-Cordobensi in Tucumania publico professore. Venetis: Apud Josephum Rosa, 1791.

MurIEL SJ, Domingo. Collectanea dogmatica de Saeculo XVIII. Aucthore D. Cyriaco Morelli, presbitero, olim in Univesitati Neo-Cordubensi en Tucumania Professore publico. Venetiis: Apud Josephum Rosa, 1792.

NIETO, Julián. Opusculum de pietate ac religione in sacro peragendo necessariis ac de tempore quod illi impedi debet auctore Juliano Nieto presbitero Hispano. Faventiae: typis Benedictis (ex typographia Archii), 1776.

ORTIZ de OCAMPO, Juan Francisco. Novena a la Virgen Maria de Monserrate, en agradecido recuerdo de sus Maravillosos portentos, la qual se venera en su capilla publica de la casa Magarola, calle de la Puerta Ferrisa. Barcellona: por Mateo Barceló, 1799.

PAge, Carlos A. Relatos desde el exilio. Memorias de los jesuitas expulsos de la antigua Provincia del Paraguay. Asunción del Paraguay: Servilibro, 2011.

Page, Carlos A. (ed.). La vida del novicio jesuita José Clemente Baigorri escrita por el P. Gaspar Juárez. Córdoba: Báez ediciones, 2012.

Pastells SJ, Pablo y Mateos SJ, Francisco. Historia de la Compañia de Jesús de la Provincia del Paraguay, t. VIII, segunda parte 1760-1768. Madrid: Consejo Superior de Investigaciones Científicas, 1949.

Paucke, Florian. Pater Florian Pauke's Reise in die Missionem nach Paraguay, und Geschichte der Missionem St. Xaver und St. Peter. Ein Beytrag zur Geschichte der Jesuiten in Paraguay. Aus der Handschrift Pauke's herausgegeben von P. Johan Frast, Cistircienser des Stiftes Zwetl und Pfarrer zu Edelbach. Viena: Bey Anton Edlem vom Schmid, 1829.

PAucke, Florián. Hacia allá y para acá (Una estada entre los indios Mocovíes, 1749-1767). Traducción castellana Edmundo Wernicke, advertencia por Radamés A. Altieri, 4 vols. Universidad Nacional de Tucumán, 1942-1944.

Pauw, Cornelius de. Recherches philosophiques sur les Américains ou Mémories..., 3 vols. Berlín, 1768-1769.

Peramás SI, José Manuel. De invento Novo Orbe inductoque illuc Christi Sacrificio Libri tres. Faenza: ex chalcographia Josephi Antonii Archii, 1777.

Peramás SI, José Manuel. Adveniente Faventiam illustrissimo ac reverendissimo episcopo DD. Dominico e Marchionibus Manciforte ad urbis praesides SS. Sabinum el Petrum Damiani. Faventiae: typis Ludovici Genestri, 1787.

Peramás SI, José Manuel. De vita et moribus tredecim virorum paraguaycorum. Faventiaen: ex typographia Archii, 1793. 
Peramás SI, José Manuel. Vida y obra de seis humanistas. Buenos Aires: Ed. Huarpes, 1946 [1791].

Quiroga, José. Tratado de el arte verdadero de navegar Pro Circulo paralelo Equinoccial que para utilidad de la marina española da a luz pública D. Manuel Mendez y Quiroga con dos figuras matemáticas y un tratadillo al fin sobre la aguja de Marear. Bolonia: En la imprenta de Santo Tomás de Aquino, 1784.

RAYNAL, Guillaume. Histoire philosophique et politique des établissements e du commerce des Européens dans les deux Indes, 5 vols. Amsterdam, 1770.

ROBERTSON, William. History of America, 2 vols. Londres: A. Strahan, 1777.

Sainz Ollero, Héctor; Sainz Ollero, Helios; Suárez Cardona, Francisco y VázQuez de CASTRO OnTAÑón, Miguel. José Sánchez Labrador y los naturistas jesuitas del Río de la Plata. La aportación de los misioneros jesuitas del siglo XVIII a los estudios medioambientales en el Virreinato del Río de la Plata, a través de la obra de José Sánchez Labrador. Madrid: Ministerio de Obras Públicas y Urbanismo, 1999.

SAlinas, María Laura y Valenzuela, Fátima V. «Los mocobíes del Chaco según la mirada del P. Manuel Canelas SJ». IHS. Antiguos jesuitas en Iberoamérica, 2015, III, 2, pp. 169-190.

SÁNCHEZ LABRADOR, José. «Gramática Eyiguayegi-Mbayá. Según el manuscrito del siglo XVIII». En SusniK, Branislava Familia Gaycurú. Asunción: Museo Etnográfico «Andrés Barbero", 1760, pp. 1-166.

SÁnchez Labrador, José. El Paraguay Católico. Homenaje de la Universidad Nacional de la Plata al XVII Congreso Internacional de los Americanistas en su reunión de Buenos Aires en mayo 16 a 21 de 1910. Buenos Aires: Imprenta de Coni Hermanos, 1910.

SANTA MARÍA, Ramón de. "El naturalista Termeyer (noticias biográficas)». En Lineo en España. Homenaje á Linneo en su segundo centenario (1707-1907). Zaragoza: Sociedad Aragonesa de Ciencias Naturales, 1907.

SANZ, José. Brevi notizie sopra l'acqua benedetta raccolte da un pio sacerdote a vantaggio de' fedeli date in luce in occasione del pubblico solenne battesimo conferito dall'illustrissimo ... Vitale Giuseppe De' Buoi vescovo di Faenza ... il dì 15 agosto dell'anno 1774 all'ebreo Moise' Leon Fuligno che nell'età d'anni 19 ha pel divina misericordia abbracciata la fede cattolica coi nomi di Giorgio Antonio Maria Abbondanzi. Faenza: per l'Archi, 1774.

SANZ, José. Elpidii de proxima bacchanalium abolitione sermo cum appendice, seu parte altera, Ec. Venetiis: 1776.

SANZ, José. Dammatio et prohibitio libri germanico idiomate editi cui titulus Was ist der Pabst Graece autem... Romae: Typographia Reverendae Camerae Apostolicae, 1786.

SANZ, José. Il leggere facilitato, o sia mettodo prattico per insegnare e imparare a leggere con poco fastidio, ed in breve tempo. Faenza: Per Giuseppe Archi, 1784 y Dissertazione critico-parenetica intorno al ministerio delle messe private in due parti. Ferrara: Per gli eredi di Giuseppe Rinaldi, 1787.

SANZ, José. Qui fidei hostes? [Tines oi tes pisteos polemioi] quali a nemici della fede? Philosophico-Theologica velitatio... Faventix: Typis Josephi Antonii Archii, 1792.

SERRANO, Giuseppe. Vera origini della souramitá temporale. Imola: Dalla Stamperia del Seminario, 1792.

Serrano, Giuseppe. Planeticoli: canti tre di Giuseppe Antonio Sornera. Lugo: Presso Giovanni Melandri, 1797. 
LA LITERATURA DE LOS JESUITAS EXPULSOS DE LA PROVINCIA DEL PARAGUAY. MEMORIAS DE UNA INTENSA LABOR

SIERRA, Vicente D. Los jesuitas germanos en la conquista espiritual de hispano-américa, siglos XVII y XVIII. Buenos Aires: Facultades de Filosofía y Teología de San Miguel e Institución Cultural Argentino-Germana, 1944.

Sommervogel SJ, Carlos. Bibliothèque de la Compagnie de Jésus. Nouvelle Édition. Tome II. Bruxelles: Oscar Schepens y París: Alphonse Picard, 1891.

Sommervogel SJ, Carlos. Bibliothèque de la Compagnie de Jésus. Nouvelle Édition. Tome III. Bruxelles: Oscar Schepens y París: Alphonse Picard, 1892.

Sommervogel SJ, Carlos. Bibliothèque de la Compagnie de Jésus. Nouvelle Édition. Tome IV. Bruxelles: Oscar Schepens y París: Alphonse Picard, 1893.

Sommervogel SJ, Carlos. Bibliothèque de la Compagnie de Jésus. Nouvelle Édition. Tome VI. Bruxelles: Oscar Schepens y París: Alphonse Picard, 1895.

STORni SJ, Hugo. Catálogo de los jesuitas de la Provincia del Paraguay (Cuenca del Plata) (1585-1768). Roma: Institutum Historicum S. I., 1980.

Storni, H. "Frías Alfaro, Alonso de. Astrónomo». En O'Neill SI, Charles E. y Domínguez, Joaquín M. ${ }^{a}$. Diccionario Histórico de la Compañía de Jesús. Biográfico-Temático, II. Madrid: Universidad Pontificia Comillas, 2001.

TERMEYER, Ramón María de. Opusculi scientifici d'entomologia di fisica e d'agricoltura dell'abate D. Raimondo Maria de-Termeyer, gaditano socio della Gia'Reale Società Agraria di Torino. Milán: nella stamperia del Giornale itálico di Carlo Nova, 1807.

URIARTE, P. José Eugenio de. Catálogo razonado de obras anónimas y seudónimas de autores de la C. de J. pertenecientes a la antigua asistencia española, I-V. Madrid: Establecimiento tipográfico «Sucesores de Rivadeneyra», 1904-1916.

Uriarte, José Eugenio de y Lecina, Mariano. Biblioteca de escritores de la C. de J. pertenecientes a la antigua asistencia de España desde sus orígenes hasta el año 1773, 2 vols. Madrid: Imprenta "Gráfica Universal», 1925-1935.

Villafañe, Diego. Esposizione scolastico-dogmatica del primo e massimo precetto della carità verso Dio. Operetta del sacerdote D. L. de V. / di Villafañe, Diego Lione de, Pubblicazione, 1792a.

Villafañe, Diego. Nuova aggiunta alla esposizione scolastico-dogmatica del precetto della carità verso Dio del medemo sacer. D. L. de V. di Villafañe, Diego Lione de, Pubblicazione, $1792 \mathrm{~b}$. 
